\title{
PROJECT
}

\section{THE MEDICAL MALPRACTICE THREAT: A STUDY OF DEFENSIVE MEDICINE*}

More suits, higher awards, and a shrinking insurance market have created a threatening atmosphere to the medical profession, prompting many physicians to prescribe unnecessary diagnostic tests as a means of insulating themselves against possible malpractice claims. The additional costs thereby generated have never been calculated, but all intelligent observers agree that they undoubtedly have contributed to the spiraling costs of medical care. $\dagger$

Since World War II the demand for medical care in the United States has increased at an unprecedented rate, largely due to the increased availability and utilization of medical insurance, as well as to expanding governmental efforts to make medical care available to all Americans, regardless of wealth or ability to pay. ${ }^{1}$ At the same

* In addition to the Editorial Board and Staff of the Duke Law Journal, Mr. David O. Smith assisted with this Project.

The Project was financed by the Committee on Legal Issues in Health Care with funds provided under Contract No. HSM 110.69-219 with the National Center for Health Services Research and Development, U.S. Department of Health, Education and Welfare. The Journal expresses its appreciation to the Committee and the National Center for this financial assistance.

The Journal wishes to express special appreciation to Professor Clark C. Havighurst, Director of the Committee on Legal Issues in Health Care, for his guidance and assistance throughout the course of the Project, and to Dr. Angell G. Beza, Director of Social Service, University of North Carolina, and Professor William M. O'Fallon, Community Health Sciences, Duke University, for their assistance in designing the survey and collating the data.

During the course of the Project over 50 interviews were conducted with specialists on the faculty of the Duke University School of Medicine and the University of North Carolina School of Medicine. The Journal also expresses its appreciation to the faculties of both schools for their kind cooperation and generous contribution of time.

$\dagger$ Eli P. Bernzweig, Relationship of Malpractice Claims to the Delivery of Health Services, 32 Prnzos, July, 1969, at 90. (Mr. Bernzweig is the Exec. Dir., Secretary's Comm'n on Medical Malpractice, Dep't of HEW).

THE FOLLOWING HEREINAFTER CITATIONS ARE USED IN THIS ARTICLE: american Osteopathic Association, Report, First National Conference on MEDICAL MALPRACTICE (1970) [hereinafter cited as AOA REPORT];

I D. Louisell \& H. Willaams, Medical Malpractice (1970) thereinafter cited as LOUISELL \& WILLINMS];

H. Somers \& A. Somers, Doctors, Patients and Insurance (1961) thereinafter cited as SOMERS]; 
time, however, the supply of medical care has not expanded sufficiently to satisfy the new demand. The result has been spiraling medical costs, increased dissatisfaction with the performance of the health care system, a growing sense of crisis ${ }^{2}$ and recognition that medical resources are seriously limited, that there is a failure to utilize the present resources efficiently, and that some alteration is essential. ${ }^{3}$

The rise in health care costs has been accompanied by a phenomenal increase in the number of suits and the size of recoveries in medical malpractice litigation. ${ }^{4}$ The resulting increased malpractice threat facing the individual physician is frequently alleged to adversely

Staff of Senate Subcomm. on Executive Reorganization of the Senate Comm. on Gov't Operations, 91 1st Cong., 1st Sess., Medical Malpractice: The Patient Versus the Physician (Comm. Print 1969) [hereinafter cited as Senate Subcomm.];

Brooke, Medical Malpractice: A Socio-Econonic Problem from a Doctors [sic] Vlew, 6 WiLLAMETTE L.J. 225 (1970) Thereinafter cited as Brooke];

Brown, Social Resource Allocation Through Medical Malpractice, 6 WILLAMETTE L.J. 235 (1970) [hereinafter cited as Brown];

Carlson, Health Manpower Licensing and Emerging Institutional Responsibility for the Quality of Care, 35 LAw \& Contemp. ProB. 849 (1970) [hereinafter cited as Carlson];

Lave \& Lave, Medical Care and its Delivery: An Economic Appraisal, 35 LAw \& ConTEMP. Prob. 252 (1970) [hereinafter cited as Lave \& Lave];

Mechanic, The Future Organization of Medical Practice, 35 LAW \& ConTEMP. ProB. 233 (1970) [hereinafter cited as Mechanic, Future Organization];

Roemer, Controlling and Promoting Quality in Medical Care, 35 LAW \& ConTeMP. ProB. 284 (1970) [hereinafter cited as Roemer];

Note, The Role of Prepaid Group Practice in Relieving the Medical Care Crisis, 84 HaRv. L. Rev. 887 (1971) [hereinafter cited as Note, Prepaid Group Practice].

1. Carlson 858; Note, Prepaid Group Practice 894-95. See Havighurst, Health Maintenance Organizations and the Market for Health Services, 35 Law \& ConTEMP. Pros. 716, 739-42 (1970); Kessel, The A.M.A. and the Supply of Physicians, 35 LAw \& ConTEMP. ProB. 267 (1970); Kessel, Price Discrimination in Medicine, I J. Law \& Econ. 20 (1954); Comment, The American Medical Association: Power, Purpose, and Politics in Organized Medicine, 63 YALE L.J. 937 (1954).

2. AOA RePort 27; SONERS 191-208; U.S. Dep't OF HEIV, Report of the NATIONAL Conference on Medical Costs (1967); Mechanic, Future Organization 233; Note, Prepaid Group Practice 891-901. But see 1 American Medical Association, Report of the Comisission on the Cost of Medical Care 39 (1964) (General Report).

3. Chapman \& Talmadge, Historical and Political Background of Federal Health Care Legislation, 35 LAW \& ConTEMP. ProB. 334, 346-47 (1970); Lave \& Lave 252.

4. It has been estimated that the number of claims increased by a factor of 10 between 1930 and 1940, and again by a factor of 10 between 1940 and 1950. AMrRICAN TRIAL LAWYERS association, Medical Malpractice-The ATL Seminar 31 (1966). The increase was so pronounced, that by $196617.8 \%$ of American physicians had experienced one or more claims during their professional careers. Id. at 32 . One insurer reported an increase of $43 \%$ in the number of claims filed during the last five years and a $200 \%$ increase in the cost per claim. It is estimated that the average cost per claim in Los Angeles, California, has risen from \$2,478 in 1957, to $\$ 13,325$ in 1970. Since 1950, six-figure judgments against physicians have become relativeiy commonplace, $i d$. at 31 , and some recent awards in California have exceeded a million 
dollars. Senate Subcomm. 8 ("Introductory Statement" by Senator Ribicoff, Chairman).

The major factor explaining the rise in litigation has been judicial liberalization of the rules governing the law of medical malpractice. E.g., AOA REPORT 6. The most significant liberalization has occurred in the use of expert testimony and the operation of the statute of limitations. Originally it was thought that a jury was incapable of judging the degree of care, judgment and skill to which the defendant physician should be held. Thus expert testimony in behalf of the plaintiff's position was required. J. WALTZ \& F. INBAU, MEDICAL JURISPRUDENCE 54-55 (1971). See also Note, The California Malpractice Controversy, 9 Stan. L. REV. 731 (1957). The phrase "conspiracy of silence" aptly described the reluctance of physicians to testify against their fellow practitioners, and the failure to locate a willing expert, for many plaintiffs, proved an insurmountable obstacle. See L'Orange v. Medical Protective Co., 394 F.2d 57 (6th Cir. 1968); Christie v. Callahan, 124 F.2d 825 (D.C. Cir. 1941); Agnew v. Parks, 172 Cal. App. 2d 756, 343 P.2d 118 (1959); Naccarato v. Grob, 12 Mich. App. 130, 162 N.W.2d 305 (1968); Belli, An Ancient Therapy Still Applied: The Silent Medical Treatment, 1 VILL. L. Rev. 250 (1956); Note, Overcoming "The Conspiracy of Silence": Statutory and Common-Law Innovations, 45 MiNN. L. REv. 1019 (1961).

To afford plaintiffs some relief from the inequity arising from the problem of expert testimony and "the conspiracy of silence," the doctrine of res ipsa loquitur was applied in the area of medical professional liability. See Comment, Res Ipsa Loquitur in Medical Malpractice Cases in Oregon, 6 WILLAMETTE L.J. 253 (1970); Note, 9 StAN. L. REV. 731, supra. Under this doctrine the plaintiff may establish a prima facie case without the use of expert testimony if he is able to show that (l) an injury has occurred which ordinarily would not occur in the absence of negligence, (2) the instrumentality causing the injury was at all times under the exclusive control of the defendant, and (3) the plaintiff was not contributorily negligent. W. PRosser, LAW OF TORTS 214 (4th ed. 1964). The doctrine has been one of the most controversial aspects of the malpractice system. Physicians despise it and urge its abolition while plaintiffs' attorneys adore it and urge its expansion, Compare Broder, Res Ipsa Loquitur in Medical Malpractice Cases, 18 DePauz L. Rev. 421 (1969) with Knisely, Modern MedicoLegal Trends, 25 OHı ST. L.J. 360, 365 (1964) and Cavero v. Franklin Gen. Benevolent Soc., 36 Cal. 2d 301, 309, 223 P.2d 471, 476 (1950) (Traynor, J., dissenting). See also Belli, I VilL. L. Rev., supra, at 262-70; Comment, 6 Willamette L.J. 253, supra; Note, 9 Stan. L. ReV., supra, at 737.

A second reaction to the "conspiracy of silence" is the introduction of medical texts in lieu of expert testimony at trial. Note, 45 MiNN. L. REV., supra, at 1034-40. A small minority of the states now allow medical texts to be admitted into evidence in strictly delineated situations. E.g., KAN. StaT. ANN. § 60-460(cc) (1964); MAss. ANN. Laws ch. 233, § 89C (Supp. 1970); Nev. Rev. Stat. \& 51.040 (1969). See also Pugh v. Stwiontek, 115 III. App. 2d 26, 32, 253 N.E.2d 3, 6 (1969); Stone v. Proctor, 259 N.C. 633, 636, 131 S.E.2d 297, 299 (1963); Burnside v. Evangelical Deaconess Hosp., 46 Wis. 2d 519, 524, 175 N.W.2d 230, 233 (1970); Lewandowski v. Preferred Risk Mut. Ins. Co., 33 Wis. 2d 69, 146 N.W.2d 505 (1966); J. WALTZ \& F. INBAU, MEDICAL JURISPRUDENCE, 85-87 \& nn.25-28 (1971).

In many states the statute of limitations was reintcrpreted as applied to medical malpractice actions. Although the general rule requires the statute to run from the actual time of the injury, in medical malpractice litigation the statute of limitations commences at the time the injury is discovered or with reasonable diligence could be discovered. E.g., ILL. REV. STAT. ch. 83, § 22.1 (1965); Flanagan v. Mount Eden Gen. Hosp., 24 N.Y.2d 427, 248 N.E.2d 871, 301 N.Y.S.2d 23 (1969); Frohs v. Greene, 253 Ore. 1, 452 P.2d 564 (1969); Sacks, Statutes of Limitations and Undiscovered Malpractice, 16 CLEV.-MAR. L. REV. 65 (1967); Recent Development, Discovery Rule: Accrual of Cause of Action for Medical Malpractice, 25 WASH. \&. LEE L. REv. 78 (1968).

In addition to a liberalization of rules governing malpractice litigation, the following have been given as reasons for the rapid increase in medical malpractice litigation: (1) Expansion 
affect the total performance of the medical care system. ${ }^{5}$ In terms of potential cost to society the most significant allegation is that the threat of malpractice litigation raises the cost of medical care by inducing physicians to overutilize diagnostic and treatment procedures-practicing what is called "positive defensive medicine." While inducement of added care is an important purpose underlying most tort liability rules, the argument is made that the benefit to the patient of the added medical care is often not worth its cost. If this allegation is true, then scarce medical resources are being diverted to rendering unjustified medical care.

Defensive medicine, consisting of medically unjustified care provided by the physician for the purpose of reducing the possibility of a malpractice suit, ${ }^{7}$ if practiced to a significant extent, represents

of professional liability insurance; (2) Greater public awareness of medical advances without a corresponding realization of medicine's inexact state; (3) An increase in all types of personal injury claims; (4) A breakdown in the personal character of the physician-patient relationship as a result of increasing medical specialization. Teahan, Malpractice $-A$ Review of 174 Claims, 35 CONN. MED. $81-82$ (1971); (5) The contingency fee system. See Note, Medical Malpractice Litigation: Some Suggested Improvements and a Possible Alternative, 18 U. FLA. L. Rev. 623 (1966). See generally F. MacKinnon, Contingent Fees for LeGAl Services 3-31 (1964); Combs, The Contingent Fees Contract, 28 TEx. B.J. 949 (1965).

5. E.g., AOA REPORT 5; Aubin, Soaring Hospital Costs-Who Is To Blame, tVashington Post, June 20, 1971, at D1, col. 1; Brooke 225; Brown 251; Mitty, How Surgical Practice is Influenced by the Legal Profession, 10 MED. TRIAL TECH. Q., June, 1964, at 29; Shanks, XRay Examination for Medico-Legal Purposes, 37 Radiologia Clinica et Brolojica 357 (1968) (British Medicine); Note, 9 StAN. L. Rev. 73l, supra note 4. But see AOA REPORT 34; Nicola, Medical Malpractice, 25 OHı ST. L.J. 378 (1964).

6. Carlson 852-53. See also Bell \& Loop, The Utility and Futility of Radiographic Skull Examination for Trauma, 284 NEw ENG. J. MED. 236, 237 \& 239 (I97) (estimating that, since only $7 \%$ of the medical-legally motivated $X$-rays yielded medically useful information, approximately $\$ 25,500$ to $\$ 37,800$ worth of $\dot{X}$-rays are wasted each year).

The term "defensive medicine" includes a physician's refusal to undertake activities which have a high risk of resulting in malpractice litigation, as well as the overutilization of diagnostic and treatment procedures. See notes $41-46$ infra and accompanying text. The phrases "negative defensive medicine" and "positive defensive medicine" have been adopted here to differentiatc between thesc two types of physician response. This Project, however, primarily deals with positive defensive medicine.

7. It is not known whether the practice of defensive medicine does in fact aid in preventing professional liability suits. Physicians are often advised, however, to practice "careful" medicine. AOA REPORT 15; Averbach, Rx for Malpractice, 19 CLEv. ST. L. REv. 20 (1970) (also in 1970 Ins. L.J. 69); Bergan, How to Avoid Malpractice Claims, 211 J.A.M.A. 2233 (1970) (recommending careful paperwork); Edelman, Professional Liability, 44 Hospitals, J.A.H.A. 54; Malpractice Prevention Workshops, A Progress Report, 112 CALIF. MED., March, 1970, at 89; Wilson, Lance and Liability, 36 THE AM. SURGEON 583 (1970). But see Law Dep't, AMA, 1963 Professional-Liability Survey, 189 J.A.M.A. 859, 861 (1964). 
a major factor in the current crisis over the cost of medical care. The most immediate cost, of course, is to the patient in the form of dollar cost and lost time. Of more consequence, however, is the "opportunity cost" or "alternate use cost" resulting from this misallocation of medical resources. ${ }^{8}$ Utilizing the physician's time and hospital facilities for defensive medicine reduces the quantity of care available for legitimate health needs, and, at a time when the demand and need for health care exceeds its supply, any such misallocation of resources is of crucial significance.

Positive defensive medicine can be sub-divided into three types of physician response. A judicial determination-in the form of a decision in favor of a patient/plaintiff that a specific diagnostic or treatment procedure should have been performed-establishes a legal standard to be met by all physicians in the geographical area. In addition, a physician may go far beyond the court-established standard by performing procedures which are neither legally nor medically required in order to guarantee that no hidden problems have been overlooked which might otherwise have become the basis of a malpractice suit. Finally, care which is neither medically nor legally required might be provided in order to create permanent documentary evidence of the patient's ailment and the physician's diligence for use in any subsequent suit.

Although frequently made, ${ }^{9}$ the allegation that a physician responds to the increased threat of a malpractice suit by practicing defensive medicine has not been verified nor has its significance been quantified. ${ }^{10}$ This Project, through a survey conducted among members of ten medical specialities in North Carolina and California, attempts to provide an empirical basis for a tentative evaluation of the allegation's validity and significance.

Defensive medicine, even if caused by the increased malpractice threat, also may be symptomatic of a lack of cost constraints in the medical care system. The physician is free to allocate medical resources to nonbeneficial uses because of the weakness of the cost

8. See Brown 249-50; Lave \& Lave 264-65.

9. See authorities cited note 5 supra.

10. E.g., Senate Subcomm. 510 (letter from Richard Bergen, Dir., AMA Legal Research Dept.); Bernzweig, 32 Pharos 90, supra note $\dagger$. The only other study found in a publication of general circulation which provides any empirical evidence of a medical-legal motivation in health care was Bell \& Loop, 284 NEw ENG. J. MED. 236, supra note 6. See also AOA RePORT 29. 
constraints which operate on him. ${ }^{11}$ Theoretically, in most industries the market forces created by consumer preferences, expressed by purchasing decisions, dictate the appropriate combinations of cost and quality and thereby limit the choices available to a producer to allocate resources to those uses which are socially appropriate. In the medical care industry, ${ }^{12}$ however, the complexity of the product-medical care-and the special relationship between physician and patient necessitate the delegation of most of the consumer/patient's decisions to the physician. ${ }^{13}$ Presently the physician is relatively independent and paid on a fee-for-service basis. ${ }^{14}$ Consequently, he occupies the unusual position of determining the need for services that he either sells himself or procures for the patient. Therefore, medical service consumption decisions are made by a party who operates, at best, under no direct cost constraint or, at worst, with a directly conflicting pecuniary interest ${ }^{15}$ creating the potential for substantial misallocation of medical resources.

In fee-for-service medicine, then, the physician may, with impunity, consider factors other than the medical benefit to the patient in deciding whether the patient should purchase additional medical care. ${ }^{16}$ One factor that might influence the physician's decision is his desire to reduce the likelihood of a malpractice suit

11. See H. Klarman, The Economics of Health 14-16 (1965); Brown 238-41. See also the authorities cited in'note 13 infra.

12. For a discussion of the economics of medical care, see, e.g., AMA REP., supra nole 2, at 7-38; HEW REP, supra note 2; H. KLARMAN, supra nole 11; Kessel, 1 J. LAW \& ECON. 20, supra note 1; Lave \& Lave 252-66.

13. Brown 240-41; Carlson 857; Lave \& Lave 259; Nicola, 25 OHı ST. L.J., supra nole 5, at 378-79. See also Louisell \& Williaiss \& 2.03. For a suggestion of a contrary view, see Mechanic, Future Organization 246.

14. Somers 51-52. See generally W. Glaser, Paying the Doctor 25, 138, 178 (1970); Carlson, 858; Mechanic, The Changing Structure of Medical Practice, 32 LaW \& ConTEMP. Prob. 707, 719 (1967), Kessel, 35 Law \& ConTemp. ProB., supra nole 1, at 279-81; Kessel, 1 J. LAw \& ECON. 20, supra note 1. On the effects of the fee-for-service system, see generally W. GLASER, supra, at 138-203.

The physician's role has been analogized to that of a "lirm manager" who delermines "on a custom basis what combinations of all other medical goods and services are 10 be produced and employed to meet the unique needs of his patient." AMA REP., supra note 2, at 10.

15. See notes 16-20 infra and accompanying text. But of. Peterson, Andrews, Spain \& Greenberg, An Analytical Study of North Carolina General Practice, 31 J. Med. EDuc., Dec., 1956, at 1, 124, 142.

16. Cf. Kessel, 35 Law \& ConTemp. ProB., supra nole 1, at 279-80; Mosma, Marglial Revenue and the Demand for Physicians' Services in EMPIRJCAl Studies in Health Economics 145 (H. Klarman ed. 1970). 
by performing or prescribing diagnostic tests and treatment procedures. ${ }^{17}$ Many other inappropriate factors might also influence the decision; indeed, there is evidence that extra hospitalization is prescribed to maximize income from facilities which carry fixed costs regardless of utilization, ${ }^{18}$ and unnecessary surgery is performed to maintain income. ${ }^{19}$ The inference of overutilization in the insured-feefor-service sector of the medical care industry is primarily based on comparisons with the performance of group practice prepayment plans. These studies show that under fee-for-service there are higher hospital admission rates, longer hospital stays, and higher minor surgery rates..$^{20}$ The data suggest, at a minimum, that the absence of cost constraints on physicians can have undesirable effects on the overall performance of the medical care industry.

The relationship between physician and patient, where the physician is entrusted with the authority to make what are, in effect, purchasing decisions, is indistinguishable from those which the law normally characterizes as fiduciary relations. ${ }^{21}$ As a fiduciary, the physician would be subject to a duty to avoid self-dealing and to subordinate his own interests to those of his patient. While judicial enforcement of the physician's fiduciary obligations to his patients would not effectively remedy the problems presented by the lack of cost constraints upon doctors, important practical consequences do or should flow from this legal characterization. Identifying the

17. See notes 4-8 supra and accompanying text.

18. Mechanic, Future Organization 247. See Note, Prepaid Group Practice 924.

19. Mosma, supra note 16; Note, Prepaid Group Practice 899-900. See also W. GLASER, supra note 14 , at $139-40,146-47$.

20. For a discussion of the studies and a comparative analysis of the two types of payment systems, see Donabedian, An Evaluation of Prepaid Group Practice, INQUIRY, September, 1969, at 3; Kessel, 35 Law \& Contemp. ProB., supra note 1, at 279-81; Note, Prepaid Group Practice. See also Havighurst, 35 Law \& Contemp. ProB., supra note 1, at 720.

For a comparative analysis concluding that there is apparently no difference in over-all costs between the two systems, see AMA REPORT, supra note 2, at 77-89.

21. The physician's duty has often been discussed in terms suggesting that it is a fiduciary duty, but usually in a context where the patient would be exposed to some bodily harm, suggesting that the corpus of the "trust" would be the patient himself and not his money. Cf. Nicola, 25 Onо St. L.J., supra note 5, at 378-80. See also Louisell \& Willuams If 2.03; Wade, Public Responsibilities of the Learned Professions, 21 LA. L. Rev. 130-31 (1960). But see Havighurst, 35 LAIV \& Contemp. Prob., supra note I, at 720; Wade, 21 LA. L. Rev., supra, at $131-33$. Such a characterization of the trust would protect the patient from many defensive medicine practices, since many also carry some degree of risk of harm, but it would not encompass those which involved only a loss of time and money, such as extra trips to the physician's office. 
relation as a fiduciary one provides an analytical framework for discussing the defensive medicine phenomenon. Also, placing a greater emphasis on the physician's fiduciary obligations should make the cost factor more prominent in the physician's decisionmaking process. ${ }^{22}$

Analysis in terms of fiduciary principles is greatly complicated, however, by the frequent presence of health insurance which pays all or most of the medical bills. ${ }^{23}$ The presence of a third-party payor fundamentally affects the physician-patient relationship by reducing the physician's duty to consider the cost of the proposed treatment and, perhaps, creating an affirmative obligation to provide the best care without regard to cost. Within the limits of the patient's insurance coverage, the physician probably feels responsible to further the patient's best interests by doing everything that is medically desirable. He can hardly be faulted for not considering the cost to the insurance company when deciding what care his patient's needs dictate. The insurance system, at a minimum, relieves the physician of the fiduciary responsibility to be cost-conscious, and greatly - exacerbates the existing propensity of our present medical care system to overutilize our medical resources. ${ }^{24}$

Given the widespread misallocation of medical resources by feefor-service providers, the problem of defensive medicine, then, may have more significance as an indicator of the weakness of cost constraints in the medical care market than of the need for an alteration to the law of medical malpractice. In addition to providing empirical data to evaluate defensive medicine, a second purpose of the survey of members of medical specialties in North Carolina and California was to evaluate the hypothesis that the practice of defensive medicine reflects a systematic failure of physicians to respond sufficiently to the cost-benefit of particular procedures before selecting among viable alternatives.

Finally, if the problem of defensive medicine is in fact significant,

22. See Mechanic, Future Organization 245-46.

23. See Magraw, The Purchase of Health Care-Payments, Controls and Quality, in HEW REP., supra note 2, at 286, 288-89. CS. Donabedian, INQUiRY, supra note 20, at 12. See generally H. KLARMAN, supra note 11, at 32; SOMERS 403-25.

24. Magraw, supra note 23, at 292.

25. G. Calabrest, The Costs of Accidents $24-33$ \& n.l (1970). Calabresi treats justice more as a constraint than a function of accident law. Id. at $24 \mathrm{n} .1$. In order to be accepted by the public, an accident law must relieve the injured party and must shift the cost to a party who can fairly be imposed with such cost. See id. at 24-26. 
possible solutions, focusing on either the malpractice threat or appropriate cost constraints, could be proposed. Malpractice litigation, however, has several distinct but interrelated effects on the health care system; altering malpractice law to correct one defect may, by changing other impacts, adversely affect the quality and quantity of medical care. The third purpose of this study is to provide a conceptual framework and some statistical evidence for evaluating the total effect of malpractice litigation on the medical care system and the desirability of modification.

The Impact of the Malpractice Suit on the Medical Care SYSTEM

Calabresi suggests that accident law has two basic functions: to minimize the costs of accidents and to do justice by shifting the cost of accidents from innocent injured parties to more appropriate cost bearers. ${ }^{25}$ The cost of accidents consists of the sum of the costs of injuries, the costs of preventing injuries, and administrative costs. ${ }^{26}$ Calabresi suggests that the first two expenses can best be minimized by locating the "cheapest cost avoider" and assigning liability to him. ${ }^{27}$ Malpractice law, like other fault-based liability law seeking to minimize costs and achieve justice, ${ }^{28}$ deters the negligent practice of medicine by compensating the innocent injured party from the pocket of the negligent physician. The prevailing assumption is that, of those parties involved, the physician is the "cheapest cost avoider" and should bear the liability where avoidable harm occurs. This conclusion is premised on the position occupied by the physician: he has access to needed information, substantial influence on the quality of medical treatment, and almost plenary authority over the type and quantity proffered. ${ }^{29}$ As noted, however, the physician, by overreacting to the threat of malpractice, increases the preventive costs without a corresponding reduction in injury costs. ${ }^{30} \mathrm{~A}$ possible inference is that the physician may not be, after all, the "cheapest cost avoider." The impact of medical malpractice litigation on medical care will, therefore, be reviewed to ascertain if malpractice

\footnotetext{
26. Id, at 26-3I.

27. See id. at 135-40.

28. Id, at 241 .

29. See notes $13 \&$ \& 14 supra and accompanying text.

30. See notes $6-8,17$ supra and accompanying text.
} 
litigation is, in fact, a viable technique for minimizing and allocating the medical care system's accident costs.

\section{Impact on Quality of Care}

The underlying assumption is that malpractice litigation reduces the costs of accidents by inducing the physician to meet a standard of care and thereby avoid accidents. ${ }^{31}$ This assumption, however, is unverified; for, while it is generally agreed that therc has been incremental improvement of the standard of medical care, ${ }^{32}$ there is little agreement or basic information concerning the amount of actual improvement attributable to successful malpractice suits. In view of the many detrimental impacts of malpractice litigation, this key question should be more fully studied.

Similarly, there is substantial disagreement concerning the need for any additional incentives on physicians. ${ }^{33}$ Indeed, some observers are more concerned that in treating an individual, physicians overemphasize quality to the detriment of the total quantity of medical resources available. ${ }^{34}$ There are many other quality incentives operating on the physician, such as humanitarian traditions, training keyed to high quality, status within the profession, and peer review..$^{35}$ Further, under a fee-for-service medical care system most physicians have little inducement to control costs to maintain profits, and corner-cutting has not presented serious quality implications. ${ }^{36}$ Nevertheless, if cost constraints on the physician are increased, it may be necessary to maintain the malpractice threat in order to induce adherence to the desired standard of care. ${ }^{37}$

Another facet of malpractice litigation having quality implications is the practice of defensive medicine. Malpractice provides an inducement both to perform extra procedures-positive defensive medicine-and to refrain from engaging in high risk procedures-negative defensive medicine. Positive defensive medicine, ${ }^{38}$ an over-reaction to the malpractice threat, has a favorable

31. See Senate Subcomm. 6.

32. Brooke 233; Roemer 297. See AOA RePORT 29, 37. But see Brown 250.

33. See note 32 supra.

34. E.g., Note, Prepaid Group Practice 926.

35. See Louisell \& Williams if 2.04; Somers 111-19; Carlson 849; Roemer 286-300. But see id. at 298.

36. Note, Prepaid Group Practice 926.

37. See Roemer 295; Note, Prepaid Group Practice 926.

38. See notes 6-8 supra and accompanying text. 
impact on the quality of care received by the individual patient ${ }^{39}$ but reduces the quantity of care delivered by the medical care system. Therefore the preventive costs may be increased without an equal reduction in injury costs..$^{40}$

Negative defensive medicine, consisting of physician refusal to undertake activities which have a high risk of resulting in malpractice litigation, presents serious quality as well as quantity implications.41 Examples of negative defensive medicine would be refusal to take emergency room duty, ${ }^{42}$ to accept patients with complicated problems, ${ }^{43}$ to use high risk techniques even though the seriousness of the patient's condition might call for their use ${ }^{44}$ to adopt new and innovative medical procedures, ${ }^{45}$ or to implement more efficient organizational techniques-such as employing physician's assistants or delegating functions. ${ }^{46}$ The probability and import of this alleged response represents a key issue in any suggestion to restrict malpractice litigation, but has never been quantified.

Finally, awareness of the possibility of a malpractice suit is frequently alleged to cause both the physician and patient to be apprehensive, creating an adverse effect on the delicate physicianpatient relationship. ${ }^{47}$ A physician normally attempts to inspire trust and confidence in his judgment in order to engender a helpful and positive attitude in the patient.48 Such "rapport" is thought to be beneficial and perhaps even essential for successful treatment. It is not clear, however, whether the deterioration of this special relationship is a cause or an effect of the increased malpractice

39. See Roemer 295 , suggesting that much of the unjustified medical care permitted by the lack of cost constraints may have the beneficial effect of assuring that a patient receives adequate attention even when the physician is under pressure.

40. See notes $25-30$ supra and accompanying text.

41. E.g., Ribicoff, Medical Malpractice: The Patient Versus the Physician, Trial, Feb./Mar., 1970 at 10-27; Waschoski \& Stronoch, The Radiologist and Professional Medical Liability, 30 Temple L.Q. 398, 399-400 (1957). See SeNate Subcomm. 453 for a discussion of the impact of Salgo v. Leland Stanford Hosp., 154 Cal. App. 2d 560, 317 P.2d 170 (1957), where the defendant physician was found liable for utilizing an innovative technique.

42. AOA REPORT 6.

43. Id.; SENATE SUBCOMM. 7.8.

44. Senate Subcomm. 7, 510; Brown 249.

45. Brooke 231.

46. See Carlson 852.

47. E.g., AOA Report 24.

48. Somers 460; Magraw, supra note 23, at 290-91; Note, Prepaid Group Practice 93940. See Donabedian, InQuiry, supra nole 20, at 25; Elsom, Elements of the Medical Process, 217 J.A.M.A. 1226 (1971); Mechanic, 32 LAW \& ConTEMP. ProB., supra note 14, at 712. 
litigation. Two conflicting arguments are made. It is suggested that increased specialization and mechanization in medical care have led to a deterioration in the plysician-patient relationship, which has removed many of the sociological restraints to bringing a suit against a physician and caused the increase in litigation. ${ }^{49}$ Conversely, the increase in litigation has been alleged to cause the deterioration in the relationship..$^{50}$ Regardless of which factor is the cause and which the effect, it should be noted that the significance of the adverse impact of malpractice litigation on the physician-patient relationship diminishes as the trend toward specialization and mechanization continues.

\section{Impact on Quantity of Care}

The allegation that physicians respond to the malpractice threat by overutilizing diagnostic and treatment procedures is potentially significant in terms of the quantity of a vailable medical care. While defensive medicine does not actually reduce the quantity of care available, it does misallocate the available resources by using them for medically unjustified purposes. ${ }^{51}$

The malpractice threat, it is alleged, reduces the quantity of care available by raising the costs of malpractice insurance. The resulting higher medical costs, making medical care less accessible to more Americans, produces a quantitative loss. ${ }^{52}$ The argument, however, is somewhat fallacious because higher costs merely reallocate the relatively fixed quantity of care, making it less accessible to the less wealthy. Also, the increase in dollar cost, rather than representing an increase in the total cost of medical care, is the result of shifting the cost of the injury, through litigation and insurance, from the injured patient to the public. ${ }^{53}$

The increased cost of malpractice insurance conceivably forces young physicians, unable to pay the high premiums, to drop out of the profession or to locate in areas with lower risks and rates..$^{54}$ This

49. AOA RePORT 8, 22; Brown 251; Mechanic, Future Organization 239. See also id. at 237 (noting the tendency of physicians to center their interests around the technical aspects of practicing medicine and neglecting the physician-patient relationship); Note, Prepaid Group Practice 938-46. See generally H. KLARMAan, supra note 11, at 126-48; Somers 27-56, 45589; Mechanic, 32 LAW \& CONTEMP. Prob. 707, supra note 14.

50. See note 47 supra and accompanying text.

51. See notes 6-8 supra and accompanying text.

52. E.g., Brooke 232-33.

53. See notes 60-61 infra and accompanying text.

54. E.g., Senate Subcomm. 9. See generally Mechanic, Future Organization 239. 
alleged but unverified effect of malpractice litigation, although probably operative in isolated instances, is doubtful as a major force in the industry.

Malpractice litigation does have a substantial impact on the quantity of medical care by forcing the medical care system to bear the costs of an expensive administrative system. ${ }^{55}$ These administrative costs result in the allocation of medical resources to activities which have little beneficial impact on the health needs of the nation. ${ }^{56}$ A non-judicial system, such as arbitration, would probably administer the accident law system at less cost to the health care industry, ${ }^{57}$ thereby allowing more medical resources to be allocated to legitimate health needs.

\section{Impact on the Physician}

The effect of a malpractice suit on the defendant-physician is great ${ }^{58}$ and furnishes the most persuasive justification for altering malpractice law. Malpractice, a pejorative term, carries with it often undeserved connotations of moral turpitude and near-criminal neglect. ${ }^{59}$ To an extent, some injuries, including those resulting from negligence, are inevitable, ${ }^{60}$ often the result of long and demanding hours kept by the physician. These injury costs should be appropriately shifted from the injured individual to all consumers of medical care; ${ }^{61}$ indeed, through the mechanism of insurance some

55. E.g., Senate Subcomm. 10; Brooke 229-30; Sanders, Money Well Spent, Trial, Feb., 1970, at 16. See G. CALABRESI, supra note 25, at 286-87.

56. One insurance company reports that only $38 \%$ of a recovery goes to the injured patient, $35 \%$ goes to the plaintiff's attorney, and the balance of $27 \%$ goes to defense and pre-trial investigation costs. SeNATE SUBCOMm. 10.

57. See Averbach, 19 Clev. St. L. Rev., supra note 7, at 34-36; Bergen, Medical Arbitration Experiments, 211 J.A.M.A. 351 (1970); Ludlam \& Hassard, Arbitration, 44 Hospitals, J.A.H.A. 58 (1970).

58. E.g., Louisell \& Williams If 1.04; Frankel, Medico-Legal Communication, 6 Willamette L.J. 193, 202 (1970); Gorney, A Doctor's Plea for Imelligent Compromise. TRIAL, May/June, 1971, at 53. See also AOA REPORT 12, 21.

59. Scott \& Herring, Medical Malpractice in Florida, 12 U. FLA. L. REv. 121, 126 (1959); Note, 9 Stan. L. Rev., supra note 4, at 732; Note, 18 U. FLA. L. REV., supra note 4, at 623 n.l. See Clark v. Gibbons, 66 Cal. 2d 399, 426 P.2d 525, 535, 58 Cal. Rptr. 125 (Tobriner, J., concurring) (1967); AOA Refort 7; C. Kramer, Medical Malpractice 3 (1965); LOUISEll \& Williams II 1.01. But see Brooke 230.

60. E.g., Lave \& Lave 257. See AOA Report 7; G. CALABresl, supra note 25, at 17; Gorney, TRIAL, supra note 58.

61. See generally Lave \& Lave 257; Saduck, Professional Liability Problems of the General Practitioner, 30 TEMPLE L.Q. 384, 386.88 (1957). 
costs are borne by all patients, but only after the stigma and trauma of a malpractice suit has been endured by the physician.

Calabresi's goal of justice ${ }^{62}$ is particularly relevant in assessing the impact on the individual physician. Society should determine if it is fair and beneficial to impose the experience of malpractice litigation on a physician in all instances of negligent injury. ${ }^{63} \mathrm{~A}$ relatively simple technique, reducing the apparent injustice, would be to allow direct action against insurers. ${ }^{64}$ While not removing the issue of fault from the case, substituting the insurer as the defendant would tend to shift the focus of the litigation away from the physician. Another alternative is no-fault liability which may offer a means of relieving the physician of the onus of a malpractice suit while still compensating the injured patient. ${ }^{65}$

\section{Impact on the Injured Patient}

Malpractice causes of action offer a means of compensation to only a very limited number of injured patients. Many injuries go uncompensated because they are undiscovered, because no negligence was involved or proven, or because of a reluctance to bring suit against a physician. ${ }^{66}$ Malpractice litigation may, therefore, fail to meet the requirements of being just. ${ }^{67}$ "No-fault" liability would increase the number of injuries which could be compensated, ${ }^{68}$ but increased compensation would increase the dollar cost of health care and, possibly, reallocate the available medical care.

62. See note 25 supra and accompanying text.

63. But see Brown $242-47$, suggesting that it is desirable to maintain the stigma of a malpractice suit since it is the only sanction arising from a malpractice judgment which cannot be shifted to other cost bearers (such as insurers or patients).

64. This has been done in some states, primarily for automobile accident liability, in order to remove the injustice arising from situations where the insured is immune from suit because of bankruptcy, insolvency, or absence from the jurisdiction, thereby preventing recovery from either the insured or the insurer. E.g., LA. Rev. Stat. ANN. \& 22:655 (1959); LA. Code Civ. Pro. art. 739 (1960); Wis. Stat. ANn. $\$ 260.11$ (1957), as amended, (Supp. 1971). See generally Louisell \& WilliaMs $\$ 20.02$, at 587 \& nn.17-22; Speidel, Extraterritorial Assertlon of the Direct Action Statute: Due Process. Full Faith and Credit and the Search for Governmental Imterest, 53 Nw. U.L. REv. 179 (1958).

65. See generally Ehrenzweig, Compulsory "Hospital-Accident" Insurance: A Needed First Step Toward the Displacement of Liability for "Medical Malpractice." 31 U. CHI. L. REv. 279 (1964); Note, 18 U. Fla. L. Rev., supra note 4, at 634-36. See also notc 68 infra and accompanying text.

66. C. Kramer, Medical Malpractice 1-2 (1965). But see Brooke 228.

67. See note 25 supra and accompanying text.

68. See note 65 supra and accompanying text. 


\section{Survey of Physicians}

\section{Survey Method}

The research team was composed of two law students, a medical student, and one student in a combined law-medicine program. The objectives of the survey were to identify diagnostic and treatment procedures which might be motivated by the malpractice threat, ascertain if they were so motivated, provide a monetary measure of the cost to society of those procedures, if possible, and determine whether physicians were considering the cost in selecting the proffered care. ${ }^{69}$

lnitial selection of suspected tests and procedures was made by sending questionnaires to 66 physicians at Duke University Medical Center, Durham, North Carolina, asking them to identify procedures which in their opinion met three conditions:

(1) It is conducted with some frequency (i.e., in more than isolated instances) in your practice or by physicians practicing in your area.

(2) It is prompted at least in part, in your judgment, by a concern about possible malpractice claims against the physician rather than by an objective concern for the patient's welfare.

(3) It involves, in your opinion, no medical benefit to the patient or no benefit sufficient to justify incurring the cost and any added risks.

This initial survey was followed by 5 one-hour interviews with specialists on the staff of Duke University Medical Center. The identification of procedures was found to be more difficult than expected because of the wide disparity of opinions among physicians as to the utility of various medical techniques. ${ }^{70} \mathrm{~A}$ physician who

69. The scope of the survey is subject to the following limitations: (I) The hypothetical situations were especially designed to elicit a response to the malpractice threat. No attempt was made to determine physician response under average patient-contact conditions; (2) The survey attempts to study only "positive" defensive medicine. "Negative" defensive medicine, the avoidance of high risk activities in order to minimize the possibility of a malpractice suit, see notes 6, 41-46 supra and accompanying text, is not included within the scope of the survey; (3) The survey uses the opinion of the responding physicians to approximate the determination of whether or not the practice described in each hypothetical is a medically desirable one. No effort has been made to test their opinions by submitting the procedures to a neutral body of experts; (4) The survey only deals with extra tests and procedures-it does not deal with the impact of malpractice on the performance of a medically justified procedure. For example, it may be clear that an X-ray should be taken of the skull but in order to be sure he has not overlooked anything the physician may take twice as much time as necessary in revieving the $\mathrm{X}$-ray. The latter response may also be "defensive medicine" but is not included within the scope of the survey.

70. The wide disparity in opinion is frequently noted by commentators. E.g., Frankel, Varying Standards of Care in Medicine, 19 CLEv. ST. L. REv. 43 (1970); Mechanic, Future Organization 245. See also notes 87-89 infra and accompanying text. 
never follows a certain technique because in his opinion it is useless will allege that other physicians utilize it for medical-legal reasons. However, a substantial portion of the profession may prescribe the particular technique, feel that it in fact has medical benefit, and deny that its use is motivated by the malpractice threat. Very few physicians suggested procedures which they personally utilized for medical-legal purposes, even though replies to all questionnaires were completely anonymous. The list of procedures compiled from the initial survey and the interviews which followed is contained in Appendix A.7

Having identified procedures in 10 specialties which might be motivated by the malpractice threat, hypothetical situations were designed for each specialty, describing a set of circumstances and suggesting a diagnostic or treatment procedure which might be followed under the circumstances. It was attempted to make the hypothetical situations detailed enough to provide the physician with information to make the situation realistic but general enough to obtain cost and frequency data from hospital or insurance company sources to extrapolate total yearly costs to society from each of the described practices.

Accompanying the hypothetical situations was a uniform set of questions. ${ }^{72}$ Question A asked the physician how often he would follow the practice described and gave possible responses ranging from "never" to "always." Question B asked his opinion of the medical benefit of the practice and gave possible responses ranging from "useless" to "useful and certainly worth the cost." The two questions were designed to give a comparison between frequency and medical benefit in order to determine whether physicians were responding to cost when making the decision presented in the hypothetical situation.

Question C asked the physician who would have followed the practice to indicate why he would have done so. Recognizing the difficulty of identifying one's own motives and the likely presence of secondary motives in decisionmaking, the study offered the physician several different choices and asked him to rank his reasons if there were more than one. For example, a procedure might be of marginal medical benefit so that the malpractice threat was just enough to

71. See p. 966 infra. tions.

72. See Appendix B, p. 968 infra for the hypothetical situations and accompanying ques- 
prompt the added care. Given the uncertainty about medical benefit in many instances, many such tests might seem to the physician to have been primarily motivated by medical reasons but in fact would not have been utilized without the presence of the malpractice threat, making "secondary" reasons important factors in the decisionmaking process.

The following possible reasons were suggested to the physician:

1. To complete the chart.

2. To rule out possible undetected disease.

3. For research purposes.

4. To add to a record which might be helpful in defense of a malpractice suit.

5. For the peace of mind of the patient or his relative.

6. To facilitate future treatment by yourself or others.

7. To comply with routine practice in your area.

The fourth reason was expected to be the primary indicator of a medical-legal motivation. "To comply with routine practice in your area" was chosen to reveal the physician's awareness of the legal standard imposed ${ }^{73}$ and was also expected to be another indicator of medical-legal motivation. The fifth reason was expected to indicate an awareness of the importance of pleasing the patient and his relatives in order to maintain a rapport and thereby avoid a malpractice suit. ${ }^{74}$

The questionnaires for each of the 10 surveyed specialties were sent to 100 practitioners in each of two states. ${ }^{75}$ The specific states

73. The standard applied by the court is whether the physician exercised that degree of skill and learning ordinarily possessed and exercised by members of the profession in good standing engaged in the same general line of practice in the same locality. E.g., Meier v. Ross Gen. Hosp., 69 Cal. 2d 420, 445 P.2d 519, 71 Cal. Rptr. 903 (1968); Williams v. Chamberlain, 316 S.W.2d 505 (Mo. 1958); Stone v. Proctor, 259 N.C. 633, 131 S.E.2d 297 (1963) (same degree of skill which others, similarly situated, possess). Although in the past physicians have been held to the standard prevalent in their locality, a recent decision has held that specialists in a metropolitan area may be measured against a national standard. Naccarato v. Grob, 384 Mich. 248, 180 N.W.2d 788 (1970).

74. For a discussion of the importance of a close relationship with a patient in order to avoid malpractice litigation, see, e.g., AOA REPORT 8; Bergan, 211 J.A.M.A., supra note 7, at 2234.

75. For some specialties there were fewer than 100 physicians. Neurology: California and North Carolina; Dermatology, Otolaryngology, Plastic Surgery, Urology: Nortb Carolina. For these groups, questionnaires were sent to $100 \%$ of the specialists.

The letter accompanying the questionnaire is reproduced in Appendix B, p. 968 infra, n. *. The letter reveals and explains the purpose of the survey. In an earlier survey asking for similar information the researchers had not revealed their purpose because of a fear that a discussion of the malpractice threat would influence the results. The response rate to that survey 
were chosen to provide a comparision between decisionmaking in a state with a high rate of malpractice claims and high malpractice insurance rates, California, ${ }^{76}$ and a state which ranks low in both of these categories, North Carolina. ${ }^{77}$ The sample was randomly drawn from a listing of all physicians in the respective states appearing in the 1969 American Medical Directory ${ }^{78}$ who stated the subject specialty was their specialty. ${ }^{79}$

Of the 1,545 questionnaires sent, 54\% were answered and returned. ${ }^{80}$ The response rate from North Carolina was consistently higher than from California, with as many as $22 \%$ more responses from plastic surgeons to as few as $10 \%$ more responses from otolaryngologists.

Since the sample population was randomly selected it included both board and non-board certified specialists ${ }^{81}$ and a spectrum of age groupings. There was concern that some groups would be screened out in the response and destroy the randomness of the sample. The percentage of board certified physicians and the percentage from various age groupings in the originally sampled population are compared with the similar statistics in the responding

was very low and many physicians objected to the unexplained investigation of their motives. The researchers concluded that in subsequent surveys it would be necessary to reveal the purpose and accept the possible sacrifice in accuraey in order to gain the cooperation of the physicians.

It is not known whether knowledge of the purpose of the survey influenced the results. Resentment of malpractice litigation and a desire to emphasize its faults may have elicited a higher response, or a reluctance to admit-even in an anonymous questionnaire-that any factors other than the patient's welfare enter into medical decisions may have reduced the malpractice response.

76. Law Dep't, AMA, 189 J.A.M.A., supra note 7, at 861.

77. $I d$.

78. Amirican Medical Association, American Medical Directory (25th ed. 1969).

79. The Directory allows each physician to supply the biographical data and to personally characterize his practice. Telephone conversation with Robert A. Enlow, Dir. of Circulation Records, AMA, Chicago, Ilinois, on Sept. 27, 1971. Questionnaires were sent only to physicians who indicated "Full Time Specialty Practice" (TOPOI). For a definition of "TOPOI" see AMA, supra note 78, at viii.

A random sample was drawn by listing each physician in each specialty, counting the number in each list, and dividing that number by one hundred. For example, the list for California dermatologists totalled 502 physicians so that every fifth dermatologist on the list was sent a questionnaire. In cases where a list ineluded 100 or less specialists the sample included all physicians listed. infra.

80. For a compilation of the rate of response for each specialty, see Appendix C, p. 972

81. See note 95 supra. 
population in Appendix C. ${ }^{82}$ There does not appear to have been a significant screening effect in either of these variables.

\section{General Conclusions}

The survey results are presented in Appendix D. ${ }^{83}$ The results from those hypothetical situations which were successful in eliciting a malpractice response or which provided information useful to the analysis of defensive medicine are presented in the charts in Appendix D. The accumulated results from all hypothetical situations are presented in the tables which follow those charts.

The results establish that the malpractice threat does induce physicians to practice some positive defensive medicine, but the practice is not extensive and does not have as significant an impact as previously alleged. In eight of the eleven hypothetical situations presented in the charts in Appendix D, over 20\% of the physicians from both states who indicated that they would sometimes follow the practice gave defense of a malpractice suit as the most or second most important reason for doing so. ${ }^{84}$

As expected, where the malpractice threat is a significant factor in inducing the practice presented, there is a corresponding response that the practice is not medically beneficial. $\mathrm{ln}$ all eight hypotheticals where over $20 \%$ of the physicians considered the malpractice threat significant, over $20 \%$ of the physicians also indicated that the practice was, at best, probably not worth its cost. ${ }^{85}$

The results, however, indicate that procedures prompted by the malpractice threat are not frequently followed. In only four of the eight hypotheticals where the malpractice threat was a significant motivational factor did more than $20 \%$ of the physicians from both states indicate that they follow the practice more than half of the time even though they considered it to be not worth its cost. ${ }^{86}$

The results support the earlier observation that there is a substantial disparity in opinions as to the medical benefit of many

82. See p. 972 infra.

83. See p. 973 infra.

84. Dermatology, both hypothetical situations; Obstetrics-Gynecology, first hypothetical situation; Orthopedics, Otolaryngology, Plastic Surgery, Psychiatry, and Urology, first hypothetical situation.

85. Id.

86. Dermatology, first hypothetical situation; Obstetrics-Gynecology, first hypothetical situation; Orthopedics, first hypothetical situation; Plastic Surgery. 
medical procedures. ${ }^{87}$ In seven of the eleven hypothetical situations presented in the charts in Appendix $D$, in at least one state the difference between the percentage of physicians indicating the practice was, at best, probably not worth its cost, and the percentage indicating it was probably or certainly worth its cost, was less than $20 \% .^{88}$ In only two of the hypothetical situations did more than $60 \%$ of the physicians from either state agree as to the cost-benefit of the practice. ${ }^{89}$

The results directly support the thesis that physicians in a state with a high malpractice threat provide procedures for medical-legal reasons more often than physicians in a state with a low threat. A greater percentage of physicians from California indicated "defense of a malpractice suit" as their reason for following the practices in all but one of the hypothetical situations reported in the charts in Appendix D..$^{90}$

Since the malpractice threat is greater ${ }^{91}$ in California, physicians in California were expected to order and provide more procedures than physicians in North Carolina. However, the survey indicates that physicians in North Carolina provide or follow the practices posed more often than physicians in California. In eight of the hypothetical situations presented in the charts in Appendix $D$, a greater percentage of physicians from North Carolina indicated they would follow the practice over $50 \%$ of the time. ${ }^{92}$ Although providing more care, physicians in North Carolina purport to do so for medical rather than malpractice reasons, ${ }^{93}$ indicating that other factors exert a greater impact on the allocation of medical resources than does the malpractice threat.

87. See note 70 supra and accompanying text.

88. Dermatology, first hypothetical situation, California; Obstetrics-Gynecology, first hypothetical situation, California; Orthopedics, both states; Otolaryngology, North Carolina; Pediatrics, North Carolina; Plastic Surgery, North Carolina; Psychiatry, both states.

89. Obstetrics-Gynecology, both states, second hypothetical situation; Urology, botlı states, second hypothetical situation.

90. The exception is Urology, first hypothetical situation.

91. See notes 76-77 supra and accompanying text.

92. Dermatology, first hypothetical situation; Obstetrics-Gynecology, both hypothetical situations; Pediatrics; Plastic Surgery; Psychiatry; Urology, both hypothetical situations.

The responses from all of the first hypothetical situations presented to each specialty were pooled to provide further proof of the greater utilization rate in North Carolina. It was found that $60 \%$ of the physicians from North Carolina as compared to $51 \%$ of the physicians from California would usually or always follow the practices presented. The difference in utilization rate was found to be statistically significant ( $\mathrm{p}$ less than 0.01 ).

93. See note 90 supra and accompanying text. 
Several factors might explain this difference in utilization rates. Given the great disparity in opinion among individual physicians on the cost-benefit of various procedures,,$^{94}$ the difference in utilization rates may reflect a state-wide disparity of opinion. Also, there may be a difference in confidence between physicians in the two states, with physicians in California having more confidence in their ability to diagnose and treat symptoms without relying on supportive procedures to double check their decisions. ${ }^{95}$ Homogeneity of training may explain the difference. The training a physician receives during medical school greatly influences the procedures subsequently adopted..$^{96}$ Although a large percentage of the physicians sampled in each state had been trained in the state in which they were practicing, ${ }^{97}$ a significantly greater number of physicians in North Carolina had received their early training at the same school. ${ }^{98}$ Finally, a significant number of physicians in California may have simply failed to meet the legally established standard so that the low utilization rate is causing the high rate of malpractice litigation.

It was thought that the survey results could be used to estimate the cost of defensive medicine on a state or national basis. However, lack of frequency and cost data made it impossible to extrapolate any total costs..$^{99}$

The survey supports the tentative conclusion that positive defensive medicine is not extensively practiced and does not have as significant an impact as previously alleged. The disagreement over the medical benefit of specific practices, ${ }^{100}$ the low rate of utilization of those practices which were prompted by the malpractice threat, ${ }^{101}$

94. See notes $70 \& 87-89$ supra and accompanying text.

95. The only controlled variable with any relevance to the degree of confidence which a physician might be expected to have is the percentage of physicians certified in their specialty by the American Specialty Boards. For a discussion of boards of certification, see Roemer 288-89. Approximately an equal number of responding physicians in eaeh state were board certified, see Appendix C, p. 972 infra, indicating that varying confidence was not a factor.

96. Phone conference witb Professor David Mechanic, Dir. of Graduate Training in Medical Sociology, U. of Wis., on Aug. 27, 1971.

97. See Appendix C, p. 972 infra. The last two columns of Appendix C show the maximum number of responding physicians who had come from the same state or had been trained in the same school.

98. Id.

99. The need for additional statistics for an evaluation of the causes and effects of malpractice litigation has been encountered and noted by other researchers. AOA REPORT 9; Brooke 227. See SOMERS 259. But see W. GLASER, supra note 14, at 150 \& n. 19.

100. See notes $87-89$ supra and accompanying text.

101. See note 86 supra and accompanying text. 
the substantial response positing medical purposes for following practices which had been selected to elicit a malpractice response, ${ }^{102}$ and the higher utilization rates in North Carolina ${ }^{103}$ all indicate that defensive medicine is not as significant as other factors in causing overutilization of medical resources. Overutilization because of other factors also accounts for the frequent allegation of defensive medicine. ${ }^{104} \mathrm{~A}$ physician who feels that a practice has no medical benefit will conclude that its use by colleagues is for medical-legal reasons. The user, however, will usually find the practice has medical benefit and deny being motivated by the malpractice threat.

While it is beyond the scope of this study to evaluate this wide disparity in opinion and frequency of use, additional cost constraints would force physicians to give more weight to the presence of medical benefit and perhaps, through confrontation, reduce the disparity in opinion and frequency of use. ${ }^{105}$

Defensive medicine when practiced represents the physician's failure to adequately weigh the cost-benefit of a procedure. The practice, not as extensive as previously believed, is probably more significant as an indicator of the weakness of cost constraints in the medical care system than of a dysfunction of the malpractice suit.

\section{Conclusions from Selected Individual Hypothetical Situations}

Dermatology. In the first hypothetical situation, the dermatologist was asked if he would order an histopathological examination of a removed nevus (mole) even though it appeared clinically benign. ${ }^{106}$ The second hypothetical situation asked if the dermatologist would make and preserve detailed records of examination and treatment as well as preserve copies of all correspondence with the patient. ${ }^{107}$ Over one-half of the dermatologists in both states indicated that defense of a malpractice suit was a primary or secondary reason for following both practices.

102. See Appendix D, p. 973 infra. In 7 of the hypothetical situations presented in the charts in Appendix D, more physicians from both states gave medical ("Rule out undetected disease" or "Facilitate future treatment") rather than medical-legal ("Defense of a malpractice suit"; "Comply with routine practice"; or "Peace of mind of the patient"; see notes 73-74 supra and accompanying text) reasons for following the practice.

103. See notes $91-98$ supra and accompanying text.

104. Sce notes $9 \& 70$ supra and accompanying text.

105. See notes 11-20 supra and accompanying text.

106. See p. 975 infra.

107. See p. 976 infra. 
The results from the second hypothetical indicate that the malpractice threat has had the beneficial impact of inducing physicians to follow a practice which they feel does have medical benefit. While $70 \%$ of the physicians in California and $50 \%$ of the physicians in North Carolina indicated defense of malpractice suit as the most or second most important reason for keeping detailed records of examinations and treatments, only $23 \%$ and $20 \%$ respectively indicated that the practice was not medically beneficial. The preparation of records has in fact been suggested as one positive effect of the increased malpractice litigation. ${ }^{108}$

Obstetrics-Gynecology. The first hypothetical situation presented to obstetrician-gynecologists asked if the physician had a nurse present during all gynecological examinations. ${ }^{109}$ Defense of a malpractice suit was the primary reason most frequently given by doctors in California for following this procedure, but doctors in North Carolina most frequently responded that peace of mind of the patient was their primary reason. Physicians in California were almost equally divided in opinion as to the medical benefit of the practice, while physicians in North Carolina clearly felt the practice had medical benefit.

The second hypothetical situation asked the obstetriciangynecologist if he would perform a $\mathrm{D} \& \mathrm{C}$ (dilation and curettage) on a twenty year old miscarriage patient who was otherwise healthy. ${ }^{110}$ The malpractice response was low. A high response had been expected because this procedure has often been singled out as one which physicians provide because of medical-legal reasons. ${ }^{111}$

Orthopedics. The hypothetical situation presented to orthopedists asked the physician whether he would order X-rays to confirm a diagnosis that a patient, a twenty year old male in otherwise good health, had bruised three ribs laterally. ${ }^{12} \mathrm{~A}$ high malpractice response was expected because the use of X-rays is often cited as an example of defensive medicine, ${ }^{113}$ and because orthopedics is a high risk specialty. ${ }^{114}$ The malpractice response was only moderate with no one

108. E.g., Roemer 297.

109. See p. 977 infra.

110. See p. 978 infra.

6.

111. E.g., Graham, Preventive Medicine, The Wall Street Journal, Jan. 8, 1971, at 1, col.

112. See p. 979 infra.

113. E.g., Senate Subcomm. 7.

114. The characterization of orthopedics as a "high risk" specialty is based on a comparison of insurance premiums as reported by the Insurance Rating Board: 
reason given by the majority of the physicians in either state for following this practice. A large number of physicians from both states indicated that they usually or always follow the practice even though they feel it is not worth its cost, indicating an inefficient use of medical resources which is not explained by the malpractice threat.

Otolaryngology. The hypothetical sitation presented to otolaryngologists asked the physician if he would initially order Xrays of the mastoids when a patient complains of dizziness present several months following trauma. ${ }^{115} \mathrm{~A}$ high malpractice response was expected because the use of $\mathrm{X}$-rays is often cited as an example of defensive medicine ${ }^{116}$ but the majority of the physicians in both states indicated that the primary reason for following this procedure was to rule out undetected disease. There was a wide disparity of opinion over the frequency with which this practice would be followed. Approximately one-half would order X-rays in this situation more than $50 \%$ of the time, and one-half less than $50 \%$ of the time.

Pediatrics. Pediatricians were asked if they would request a psychiatric consultation after making the preliminary diagnosis of "hyperkinetic child." 117 The malpractice response was very low with facilitation of future treatment being the reason most frequently given for following this practice. The response to questions A and B indicated that pediatricians may be failing to provide care which they feel is economically justified. Pediatrics is a low risk specialty, ${ }^{118}$ and this result may indicate that in some instances the malpractice threat should be even greater. The result may also be explained by the fact that most pediatricians refer a hyperkinetic child to a medical center and let the specialists at the center take care of psychiatric

\begin{tabular}{lcc}
\hline Specialty & North Carolina premium/year & California premium/year \\
\hline Dermatology & $\$ 35$ & $\$ 278$ \\
Pediatrics & 35 & 278 \\
Psychiatry & 35 & 278 \\
Otolaryngology-with Plastic Surgery & 140 & 1112 \\
Urology & 140 & 1112 \\
Obstetrics-Gynecology & 175 & 1390 \\
Orthopedics & 175 & 1390 \\
Plastic Surgery & 175 & 1390
\end{tabular}

Insurance Rating Board, Physicians', Surgeons' and Dentists' Liability Manual. (rev. ed. 1970) (rates eff. May 27, 1970). See also Senate Subcomm. 2.

115. See p. 980 infra.

116. See note 113 supra and accompanying text.

117. See p. 981 infra.

118. See note 114 supra. 
consultations. ${ }^{119} \mathrm{~A}$ further explanation may be that the consultations would be inconvenient and expensive, especially in rural North Carolina where a lone pediatrician often practices in a county with no psychiatrists in residence. ${ }^{120}$

Plastic Surgery. Plastic surgeons were asked if prior to an operative procedure they photograph the patient, show the photographs to the patient, and ask him to sign a statement. ${ }^{121}$ The malpractice response was very high in California but more moderate in North Carolina, but the sample size for North Carolina was so small that reliable conclusions for that state are impossible. As expected with a high risk specialty like plastic surgery, ${ }^{122}$ the response to Questions A and B indicates a substantial failure to give cost its proper weight in deciding to follow this practice. There was a very wide disparity as to frequency, but this may have been caused by the wording of the question. Taking pictures before plastic surgery is a very routine practice in close to $100 \%$ of the cases. ${ }^{123}$ Few of the physicians, however, actually show the photographs to the patient and fewer still request that the patient sign a statement. ${ }^{124}$ The hypothetical situation, however, was presented in such a way that a physician would have to do all three things in order to answer that he followed the practice.

Psychiatry. The first hypothetical situation asked the psychiatrist if he makes and preserves detailed records of examination and treatment as well as preserving all correspondence with a patient who exhibits symptoms of paranoia. ${ }^{125}$ The malpractice response was expected to be high. Although to facilitate future treatment was the first reason given by a majority of the physicians in both states, defense of a malpractice suit was the second most frequently given reason. The response to Questions A and B again indicated that the malpractice threat was having the positive effect of inducing physicians to follow a medically beneficial practice. ${ }^{126}$

119. Interview with Dr. Lois Ann Pounds, Assistant Professor of Pediatrics, Duke Medical Center, in Durham, North Carolina, Sept. 7, 1971.

120. Questionnaire comment by a respondent from North Carolina.

121. See p. 982 infra.

122. See note 114 supra and accompanying text.

123. Interview with Dr. Lawrence K. Thompson, III, Assistant Professor, Plastic and Oral Surgery, Duke Medical Center, in Durham, North Carolina, on Sept. 7, 1971.

124. Id.

125. See p. 983 infra.

126. See note 108 supra and accompanying text. 
Urology. The first hypothetical situation asked the urologist if he would order an intradermal skin test in order to evaluate whether the patient is allergic to the radio-opaque solution used in renal arteriography. ${ }^{127}$ Defense of a malpractice suit was the reason most frequently given by physicians in both states for following this practice. There was general agreement that the test was not worth its cost, and only a small percentage of the physicians indicated they would follow the practice, explaining the very low rate of response to Question C.

The second hypothetical situation asked if the urologist would administer antibiotics to combat possible genitourinary system infection following urinary bladder instrumentation. ${ }^{128}$ The malpractice response was very small. Interestingly, half the physicians usually followed the practice and half usually did not follow it. This wide variance in frequency may be explained by the fact that there is no conclusive evidence that antibiotics have any effect at all. Consequently, the physicians who frequently follow this practice do so because in their clinical experience the antibiotics are effective to fight infection, ${ }^{22}$ a conclusion which is supported by the low malpractice response from Question $C$. The response to Questions $A$ and $B$ indicated that in some instances physicians may be failing to follow practices which are of medical benefit. ${ }^{130}$

\section{SUMMARY}

The threat of a malpractice suit does induce physicians to overutilize diagnostic tests and procedures in particular cases, but the survey results support the tentative conclusion that the practice is not extensive and probably not a contributing factor to the rising costs of medical care. The survey does indicate, however, that significant overutilization of our medical resources occurs and can be explained only by factors other than malpractice litigation. The empirical data from this study, as well as others, indicate that the weakness of cost constraints operating on physicians is one of the more important of these factors. An increase in cost constraints would, therefore, have

127. See p. 984 infra.

128. See p. 985 infra.

129. Interview with Dr. Floyd Fried, Associate Professor of Urology, University of North Carolina Medical Center, Chapel Hill, North Carolina, on Sept. 10, 1971.

130. See also the text accompanying note 118 supra. 
a greater effect in improving the efficiency with which medical resources are used than an alteration in the law of medical malpractice.

Malpractice litigation, however, does have several other adverse impacts which merit further consideration and may provide independent justification for modifying the law of medical malpractice. It may induce negative defensive medicine. Empirical data should be developed to verify and measure this impact. A substantial and often undeserved stigma and trauma is imposed on a defendant physician. The long-term adverse effects of this impact, while not substantial, may not be justified hy the limited gains from malpractice litigation. Malpractice litigation also imposes tremendous administrative costs on the health care system in discovery costs and attorney and court fees. For these costs, malpractice litigation makes only a questionable contribution to the maintenance of an acceptable standard of care and spreads the costs of only those injuries received by a very limited class of patients. It should be determined if these doubtful beneficial effects are worth the cost.

The presence of cost pressures and the practice of high quality medicine, however, may be inversely related. If the physician is forced to give cost greater weight, the importance of the malpractice threat as a technique for assuring high quality care may increase. The major concern today is with the quantity of care available, and is likely to lead to the imposition of additional cost constraints as a technique for increasing that quantity. ${ }^{131} \mathrm{~A}$ reduction of the malpractice threat should be considered only after experience has been gained with the combined effect of cost constraints and high malpractice threat as means of assuring a proper balance of quantity and quality.

131. See, e.g., Havighurst, 35 LAW \& CONTEMP. Prob. 716, supra note 1. 


\section{APPENDIX A}

\section{List of Suspected Tests and Procedures Obtained from Initial Survey and Interviews}

\section{Anesthesiology}

1. Overutilization of serum electrolytes (sodium, potassium, chloride).

2. Determinations of oxygen and carbon dioxide content of blood and acidity of blood done by multiple samples.

\section{Dermatology}

1. Removed nevi (moles) are sent to pathology department for histopathological examination.

\section{Internal Medicine}

1. Skull $x$-rays, especially in emergency cases.

2. In-hospital patients suffering minor trauma, such as a fall, without external signs of injury or loss of consciousness, are frequently over x-rayed.

3. In evaluation of headaches and in cases of abnormal behavior workups, brain scan, EEG, and skull films overused.

4. For gastrointestinal ailments, upper and lower GI series, gall bladder exam, barium enema, and small bowel follow-through are ordered.

5. Electrolytes.

6. In the gastroenterology sub-specialty, procedures such as endoscopy, liver biopsy, bowel biopsy, and exploratory laparotomy are overutilized.

7. Nasal bone $x$-ray to rule out fracture.

8. Use of tetanus vaccine in the emergency room.

9. Consultations requested on head injury.

10. Prophyiactic antibiotics overutilized and biological culture to determine adverse reaction to antibiotics.

11. Post-operative blood chemistries designed to uncover obscure liver infection or blood count abnormalities.

\section{Neurology}

1. Blood chemistries as routine admittance practice.

2. Over $x$-ray spine, skull, and chest. "Less than $5 \%$ of $x$-rays done on emergency patients are done for no reason other than medico-legal aspects. About $10 \%$ of cervical and lumbar spine $x$-rays for patients in pain are for the same reason."

3. Blood counts, blood chemistries, urinalysis, VDRL, brain scan, EEG, EKG. "Skull $x$-rays are obtained on almost all patients who have headache or recent head injury . . . Similarly brain-wave tests in patients with headaches are only rarely of value."

\section{Orthopedics}

1. X-rays of suspected fractured toe, ribs, and ankle. 
2. Myelograms routinely ordered preceding cervical and lumbar spine fusions.

3. Patient returns on the day following the reduction of fracture so that physician can evaluate circulation and sensation.

4. Post-operative $x$-rays or $x$-rays in the operating room.

5. Consultation with neurologist if patient has a headache.

\section{Otolaryngology}

1. X-rays of nose in case of suspected fracture.

2. X-rays of mastoids and petrous bones for all forms of dizziness, particularly those present months or even years after trauma.

3. Caloric tests (vestibular function tests) for all forms of dizziness.

4. Audiograms for evaluating all forms of dizziness.

\section{Pediatrics}

1. Skull films on a child who bumps his head while in-hospital patient, even if there is no trauma or only slight trauma.

2. Admission chemistries.

3. Bone age films.

4. Thyroid tests.

5. Spinal taps done with first febrile convulsion.

\section{Plastic Surgery}

1. Too many $x$-rays in accident cases.

2. Photographs in black-white-color taken to show pre- and postoperative conditions.

\section{Psychiatry}

1. X-rays of spine, skull, EEG, and EKG for pre-electroshock therapy workups.

2. Blood counts.

3. Check on liver functioning for patients on psychoactive drugs used in psychotherapy.

4. Pediatricians and physicians refer patients to psychiatrists because of legal implications.

5. Additional interviews and psychological tests ordered if the case is likely to terminate in court.

6. More careful and detailed documentation of findings and recommendations when the patient (or parents) have paranoid tendencies.

\section{Urology}

1. Aortography in kidney cysts.

2. Chest x-rays.

3. Repeated intravenous pyelograms.

4. Electrocardiograms. 


\section{APPENDIX B}

\section{Questionnaire}

Each questionnaire consisted of one or several hypothetical situations with a uniform set of three questions following each hypothetical situation. The hypothetical situations presented to each speciality are reproduced below and the set of three questions follows. The questionnaires were sent to specialists along with a cover letter under the letterhead of the Committee on Legal Issues in Health Care.*

\section{Hypothetical Sitúations Posed}

\section{Dermatology}

1. Even though removed nevi appear clinically benign, the dermatologist orders histopathological examination.

2. The dermatologist makes and preserves detailed records of examination and treatment as well as preserving copies of all correspondence with the patient.

\section{Internal Medicine}

1. Upon entering the hospital with a preliminary diagnosis of carcinoma of the lung, the patient undergoes certain routine tests. One of these is "admission chemistries," or the full battery of serum electrolytes.

2. The patient is admitted to the hospital with non-specific abdominal complaints. On the day of admission he undergoes electrocardiography.

3. Same situation as in (2) above. The patient undergoes an upper GI series.

4. Same situation as in (3) above. The patient undergoes a lower GI series.

5. Same situation as in (4) above. The patient undergoes proctoscopy.

\section{Neurology}

1. A student appears at the campus health office with the complaint of headache for the duration of three days. The physician orders skull $x-$ rays.

2. In a work-up for probable intra-cranial tumor, the patient has undergone skull $\mathrm{x}$-rays, cerebral arteriography, echoencephalography, and ventriculography. The neurologist orders an electroencephalogram.

\section{Obstetrics-Gynecology}

1. A female nurse is present during all gynecological examinations of the patient. 
2. The gynecologist performs a $D \& C$ (dilation and curettage) on a twenty year old miscarriage patient who is otherwise healthy.

\section{Orthopedics}

1. After taking the history and performing a physical examination, the orthopedic specialist determines that the patient, a twenty year old male in otherwise good health, has bruised three ribs laterally. He orders $\mathrm{x}$-rays to confirm his diagnosis.

2. A fracture of the tibia is reduced and cast applied. The orthopedic specialist requests that the patient return the following day for a reexamination of circulation and sensation in the leg.

\section{Otolaryngology}

1. When the patient complains of dizziness present several months following trauma, the otolaryngologist initially orders $x$-rays of the mastoids.

2. In evaluating all forms of dizziness, the specialist initially performs audiograms.

\section{Pediatrics}

1. After making a preliminary diagnosis of "hyperkinetic child," the pediatrician requests psychiatric consultation.

\section{Plastic Surgery}

1. Prior to an operative procedure, the surgeon has photographs of the patient taken, shows the photographs to the patient, and has the patient sign a statement that each photograph is an accurate likeness.

\section{Psychiatry}

1. When the patient exhibits symptoms of paranoia, the psychiatrist makes and preserves detailed records of examination and treatment as well as preserving all correspondence with the patient.

2. Before prescribing psychoactive drugs, the psychiatrist performs a physical examination of the patient.

\section{Urology}

1. The patient is to undergo renal arteriography. The urologist orders an intradermal skin test in order to evaluate whether the patient is allergic to the radio-opaque solution used.

2. Following urinary bladder instrumentation, the urologist administers antibiotics to combat possible genitourinary system infection. 


\section{Set of Questions Following Each Hypothetical Situation}

A. Would you have followed that practice? (Please check one)
(I)__Never.
(2)_Seldom (less than $10 \%$ of the time).
(3)___ Occasionally ( $10-49 \%$ of the time).
(4)___ Most of the time (50-90\% of the time).
(5)____Almost invariably (over $90 \%$ of the time).

B. Do you believe that that practice would be of medical benefit to the patient? (Please check one)
(1)___Useless.
(2)______ Somewhat useful but not worth the cost.
(3)___Useful but probably not worth the cost.
(4)___Useful and probably worth the cost.
(5)___Useful and certainly worth the cost.

C. If you would have followed that practice, please answer why. If more than one reason applies, number them in order of importance with number one being the most important reason for following that practice.

(1)_To complete the chart.

(2)___ To rule out possible undetected disease [Not applicable to all hypothetical situations.]

(3)__ For research purposes.

(4) __ To add to a record which might be helpful in defense of a malpractice suit.

(5) ___ For the peace of mind of the patient or his relatives.

(6)_____ To facilitate future treatment by yourself or others.

(7)___ To comply with routine practice in your area.

(8)___ Other (SPECIFY): 099

\footnotetext{
* Dear Doctor:

This Committee [Committee on Legal Issues in Health Care] is sponsoring a study of the effect of the threat of malpractice claims on the medical decisions of physicians when ordering diagnostic tests. It is widely and repeatedly asserted that the threat of malpractice suits causes physicians to order tests or take other precautions which are not medically beneficial to the patient but which could be utilized in the physician's defense in a future court proceeding. Our research on this subject is designed to appraise the amount of truth in this assertion and to identify as precisely as possible the areas in which medical resources may be overutilized.

Your cooperation in responding to the questionnaire will be most helpful in making the study comprehensive and useful. Your answers will be absolutely confidential, and no individual's answers will be revealed in the report of this study to be published in the Duke Law Journal, a publication of the Duke University School of Law. On the basis of a statistical analysis of the answers to the questionnaire, the report may propose changes in the law of malpractice or changes in the standards of the medical profession to minimize waste.
} 
Your name will not appear on the questionnaire, but we will appreciate your signing the attached post card and returning it separately to us. This will indicate that you have returned your questionnaire without our knowing which questionnaire is yours. If you are interested in receiving a report of the study, you may request a copy at no cost from the Project Editor, Duke Law Journal, Duke University Law School.

Thank you very much for your help.

Director,

Committee on Legal lssues in Health Care 


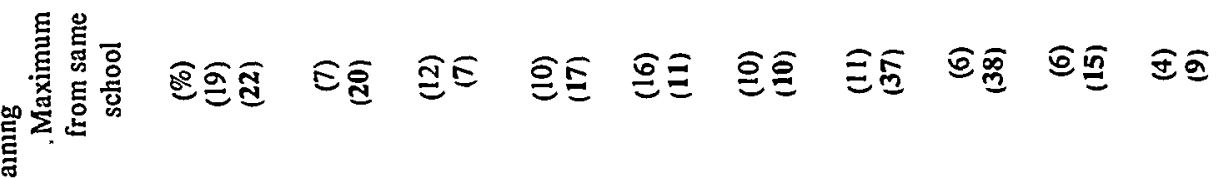
苞

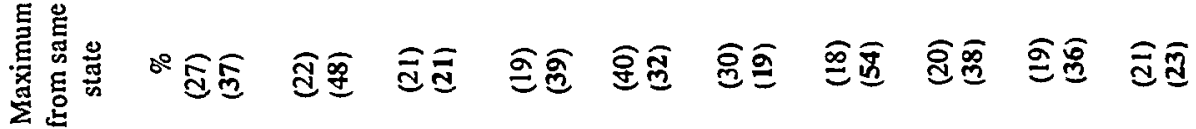

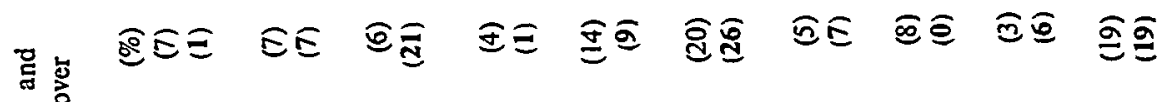

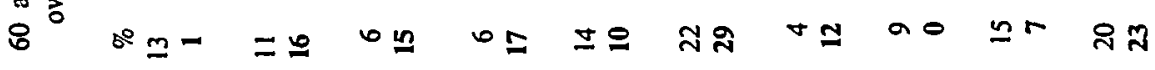

严

ह 严总旁

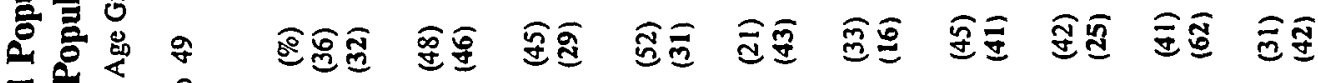

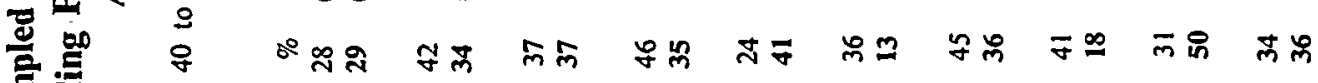

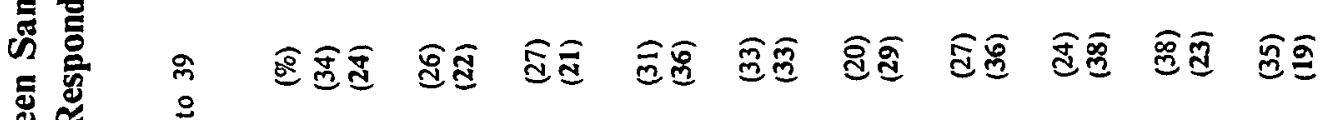

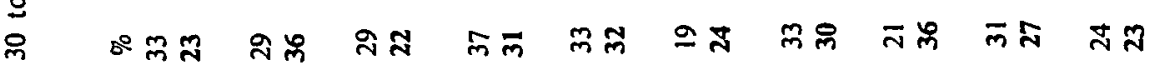

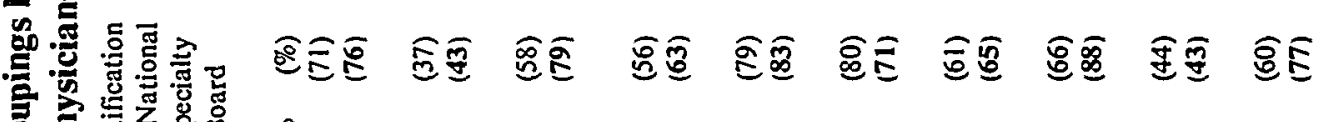

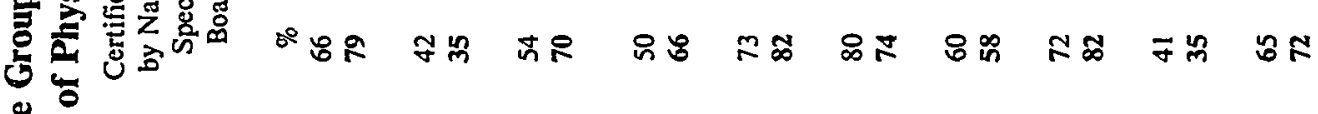
:

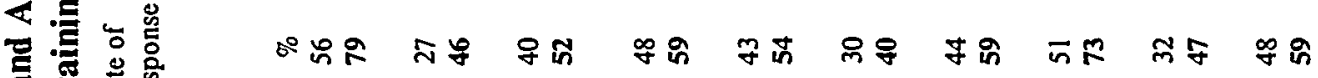

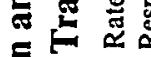

융

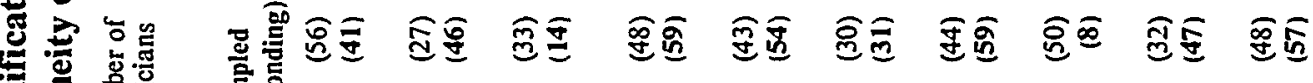

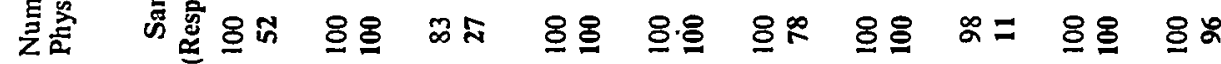

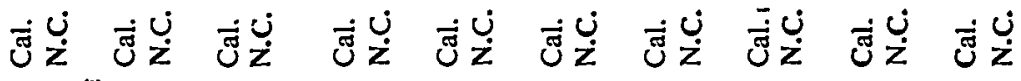

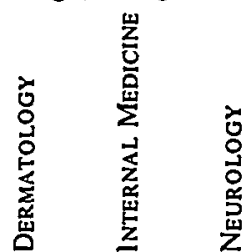

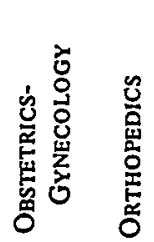




\section{APPENDIX D}

\section{Survey Results}

The results from those hypothetical situations which were successful in eliciting a malpractice response or which provided information useful to the analysis of defensive medicine are presented in the charts on pages 975-85 infra. The accumulated results from all hypothetical situations are summarized in tables on pages $986-93$ infra.

Figure 1 of each chart page cross-tabulates responses to Question A-How often would the physician follow the practice described?-and Question B-Did the physician believe the practice was worth its cost? For example, for Dermatology, hypothetical situation number one (page 975 infra), the section in the next to the last column and in the top row of Figure 1 indicates that $4 \%$ of the dermatologists in California and $0 \%$ of the dermatologists in North Carolina always order a histopathological examination of a removed nevus even though they feel the practice is of no value to the patient. The bottom row of Figure 1 of each chart page shows the total response to Question A. For example, 53\% of the dermatologists in California and $71 \%$ of the dermatologists in North Carolina always follow the practice of ordering a histopathological examination of a removed nevus. A response in the shaded portion of Figure 1 indicates failure to give adequate consideration to cost. A physician whose response falls in this area would follow the practice more than $50 \%$ of the time even though he believes it is, at best, "probably not worth the cost." For example, 27\% of the dermatologists in California and 28\% of the dermatologists in North Carolina order a histopathological examination of a removed nevus more than $50 \%$ of the time even though they feel the practice is probably not worth the cost.

Figure 2 of each chart page presents the results from Question C-Why would the physician have followed the practice?- by showing the percentage of physicians from each state who marked each reason as their first or second reason for following the practice described. For example, defense of a malpractice suit was indicated as their first reason for ordering a histopathological examination of a removed nevus by $38 \%$ of the dermatologists in California and $23 \%$ of the dermatologists in North Carolina. It was indicated as either the first or second reason by $59 \%$ and $52 \%$ respectively. To rule out undetected disease was indicated as the first reason by $41 \%$ of the dermatologists in California and $48 \%$ of the dermatologists in North Carolina, and either the first or second reason by $50 \%$ and $64 \%$ respectively.

The accumulated results from all hypothetical situations, including those which failed to elicit a malpractice response, are presented in the tables on pages 986-93 infra. The first table presents the results from Question A, 
showing the percentage of physicians who answered each of the frequency choices, from "Never" to "Always," and the results from Question B, showing the percentage of physicians who answered each of the medical benefit choices, from "Useless" to "Certainly Worth the Cost."

The second table presents the results from Question $C$, showing the percentage of physicians who indicated each of the reasons as (1) their first reason, (2) their first or second reason, and (3) their first, second or third reason. The second and third reasons have been included because it was felt that "secondary" reasons are important factors in the decision-making process. In many instances the presence of the malpractice threat might be just enough to justify following a marginal practice. Although primarily motivated by medical reasons, such practices would not have been followed without the presence of the malpractice threat. 


\section{DERMATOLOGY}

Even though removed nevi appear clinically benign, the dermatologist orders histopathological examination.

Figure 1. Cross-tabulation showing frequency sample physicians in California (Cal.) and North Carolina (N.C.) follow practice compared with their opinions as to utility of practice. Response in shaded area indicates failure to consider cost. (Sample Size: 56 Cal.; 44 N.C.)

\section{FREQUENCY (\% Cal./\%N.C.)}

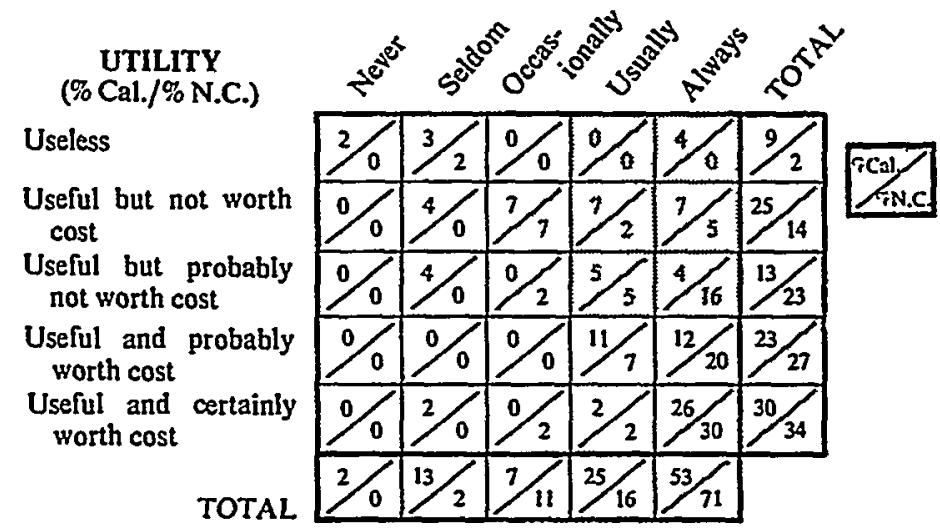

Figure 2. The first and second most important reasons to sample physicians for following this practice. (Sample size: 58 Cal.; 44 N.C.)

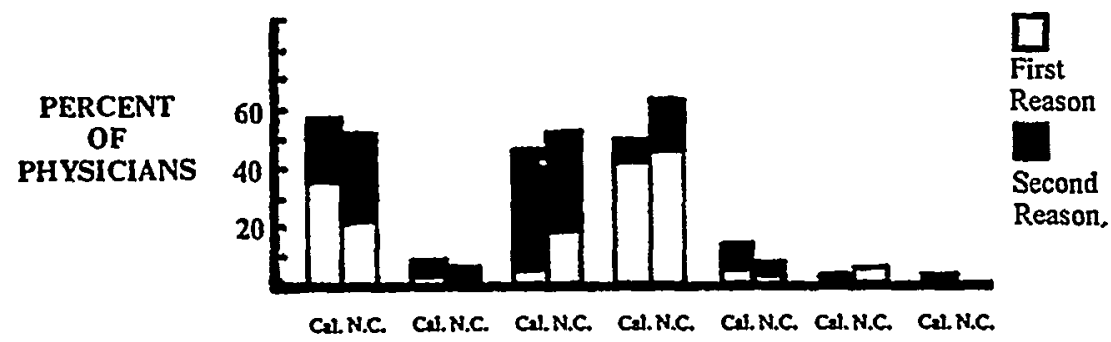

\begin{tabular}{|c|c|c|c|c|c|c|}
\hline $\begin{array}{l}\text { REASONS } \\
\text { FOR } \\
\text { FOLLOWING } \\
\text { PRACTICE }\end{array}$ & 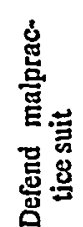 & 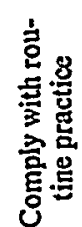 & 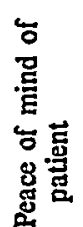 & 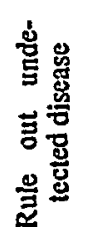 & 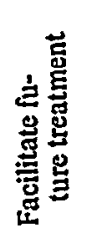 & 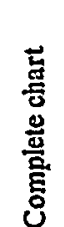 \\
\hline
\end{tabular}




\section{DERMATOLOGY}

The dermatologist makes and preserves detailed records of examination and treatment as well as preserving copies of all correspondence with the patient.

Figure 1. Cross-tabulation showing frequency sample physicians in California (Cal.) and North Carolina (N.C.) follow practice compared with their opinions as to utility of practice. Response in shaded area indicates failure to consider cost. (Sample Size: 57 Cal.; 44 N.C.)

FREQUENCY (\%Cal./\%N.C.)

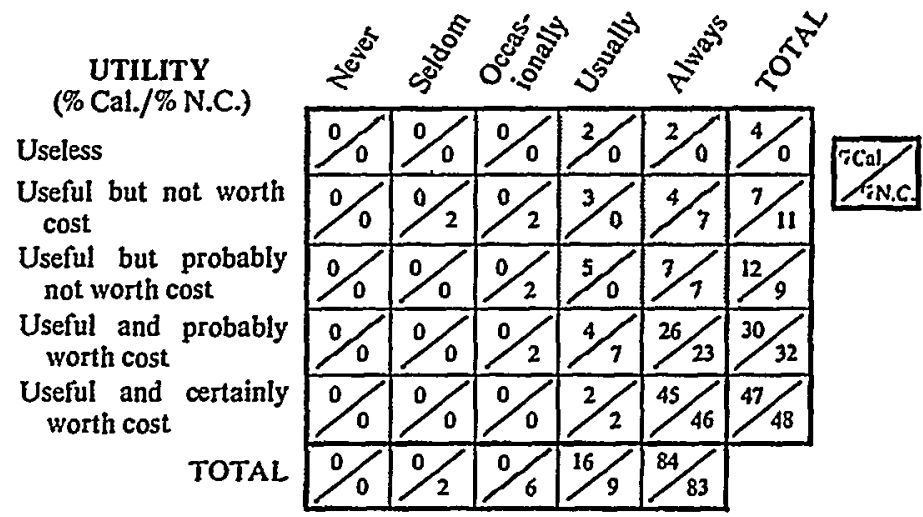

Figure 2. The first and second most important reasons to sample physicians for following this practice. (Sample size: 58 Cal.; 44 N.C.)

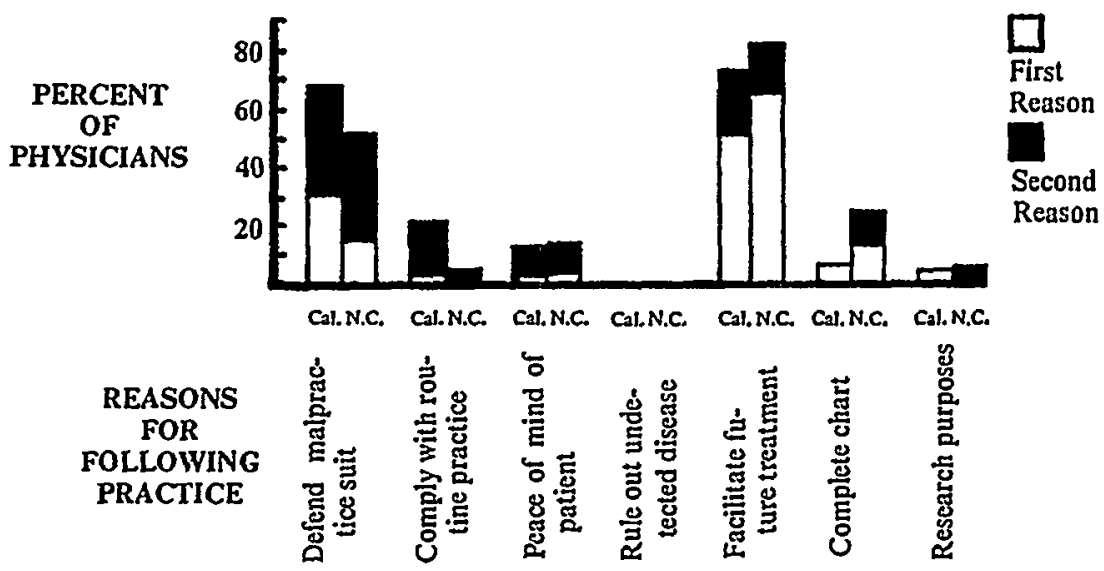




\section{OBSTETRICS-GYNECOLOGY}

A female nurse is present during all gynecological examinations of the patient.

Figure 1. Cross-tabulation showing frequency sample physicians in California (Cal.) and North Carolina (N.C.) follow practice compared with their opinions as to utility of practice. Response in shaded area indicates failure to consider cost. (Sample size: 48 Cal.; 64 N.C.)

\section{FREQUENCY (\%Cal./\%N.C.)}

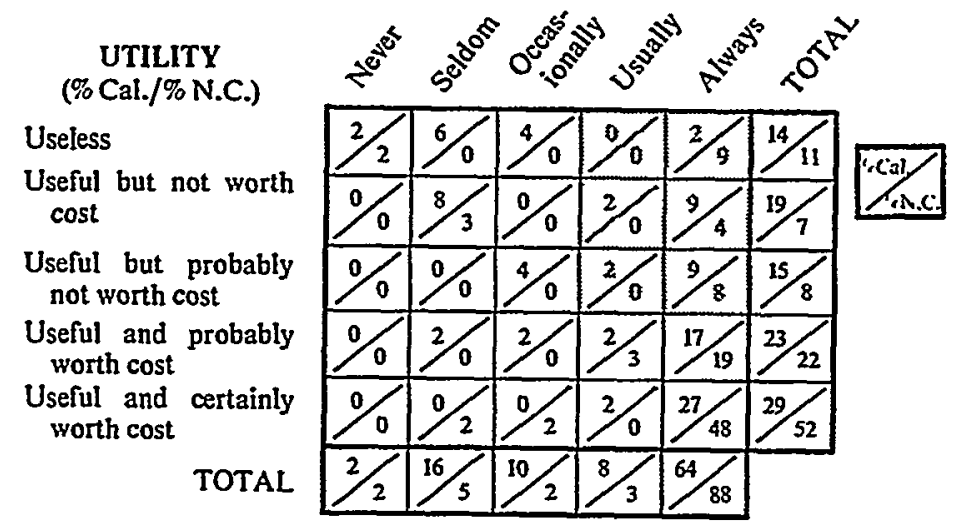

Figure 2. The first and second most important reasons to sample physicians for following this practice. (Sample size: 49 Cal.; 64 N.C.)

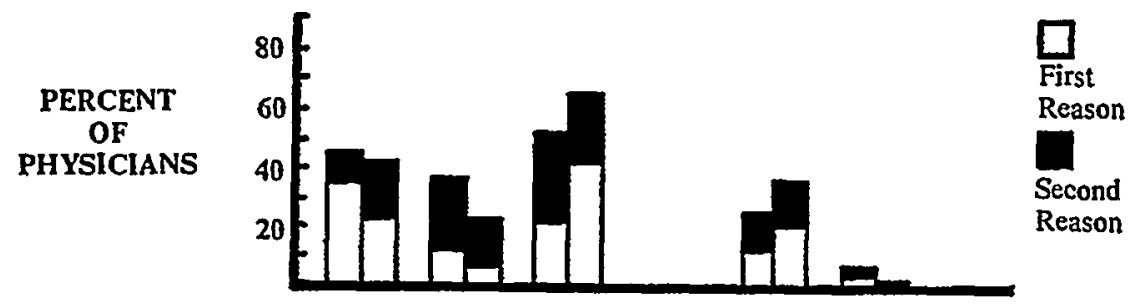

Cal.n.C. Cal.n.C. Cal.N.C. Cal.N.C. s-l.N.C. Cal.N.C. Cal.N.C.

\begin{tabular}{|c|c|c|c|c|c|c|}
\hline $\begin{array}{l}\text { REASONS } \\
\text { FOR } \\
\text { FOLLOWING } \\
\text { PRACTICE }\end{array}$ & 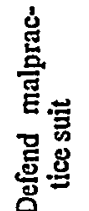 & 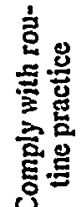 & 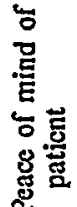 & 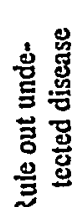 & 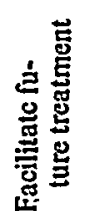 & 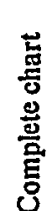 \\
\hline
\end{tabular}




\section{OBSTETRICS-GYNECOLOGY}

The gynecologist performs a $D \& C$ (dilation and curettage) on a twenty year old miscarriage patient who is otherwise healthy.

Figure 1. Cross-tabulation showing frequency sample physicians in California (Cal.) and North Carolina (N.C.) follow practice compared with their opinions as to utility of practice. Response in shaded area indicates failure to consider cost. (Sample size: 47 Cal.; 63 N.C.)

\section{FREQUENCY (\%Cal./\%N.C.)}

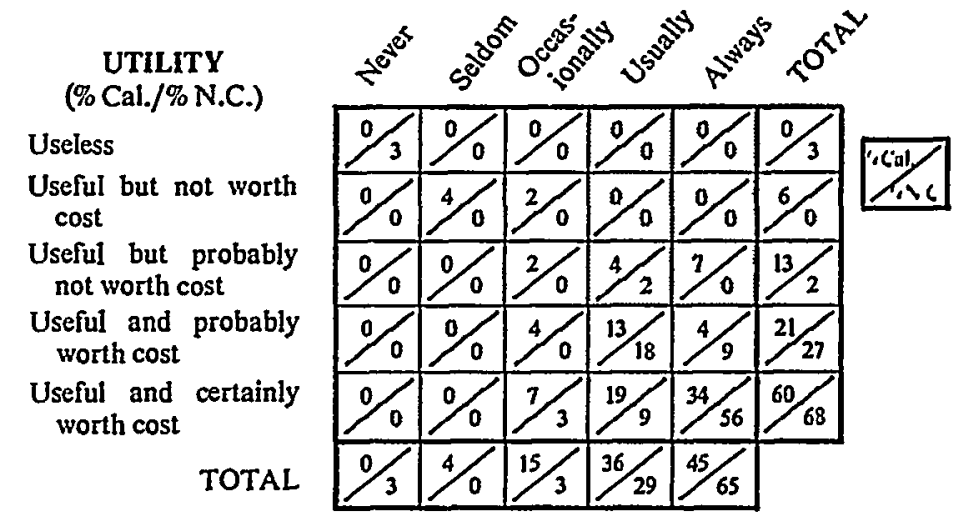

Figure 2. The first and second most important reasons to sample physicians for following this practice. (Sample size: 49 Cal.; 64 N.C.)

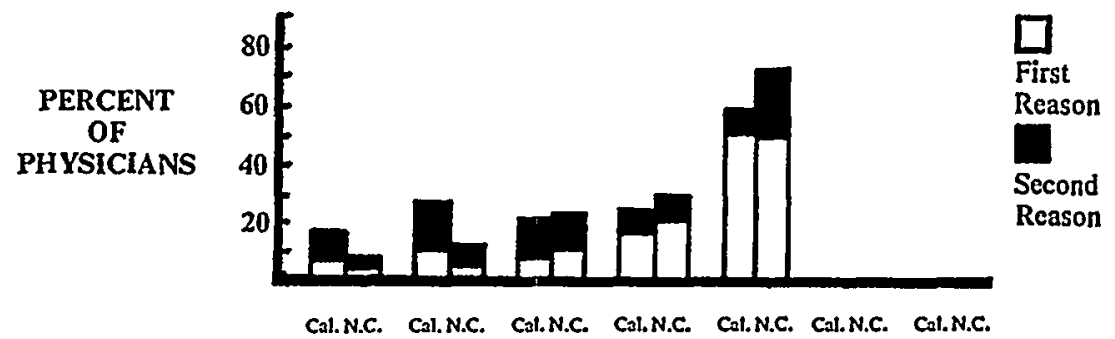

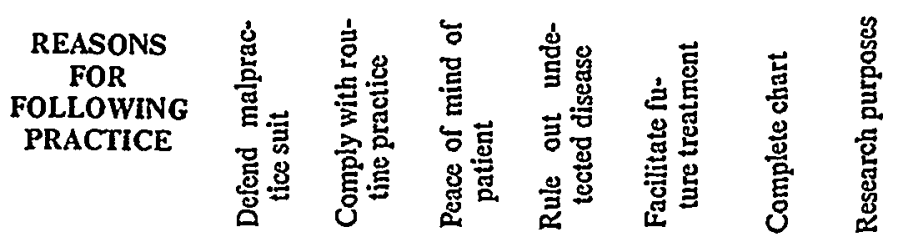




\section{ORTHOPEDICS}

After taking the history and performing a physical examination, the orthopedic specialist determines that the patient, a twenty year old male in otherwise good health, has bruised three ribs laterally. He orders X-rays to confirm his diagnosis.

Figure 1. Cross-tabulation showing frequency sample physicians in California (Cal.) and North Carolina (N.C.) follow practice compared with their opinions as to utility of practice. Response in shaded area indicates failure to consider cost. (Sample size: 50 Cal.; 57 N.C.)

FREQUENCY (\%Cal./\%N.C.)
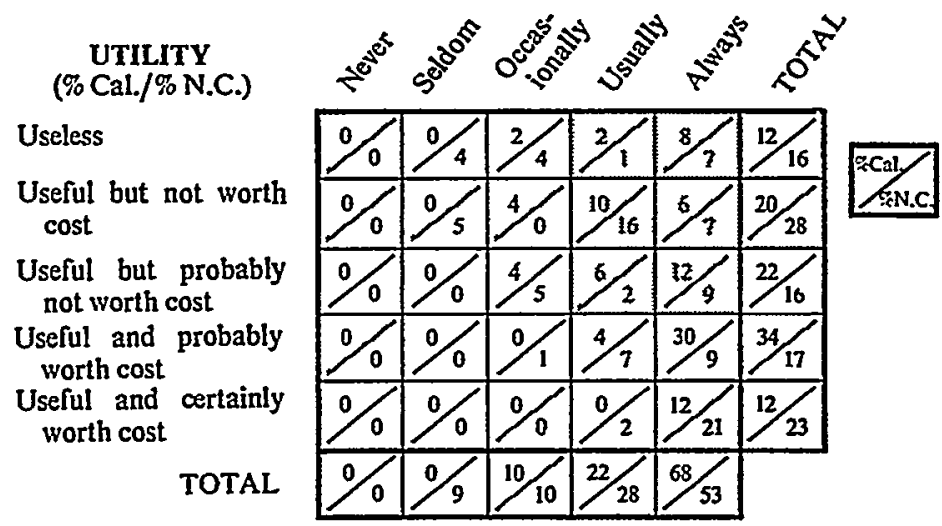

Figure 2. The first and second most important reasons to sample physicians for following this practice. (Sample size: 50 Cal.; 58 N.C.)

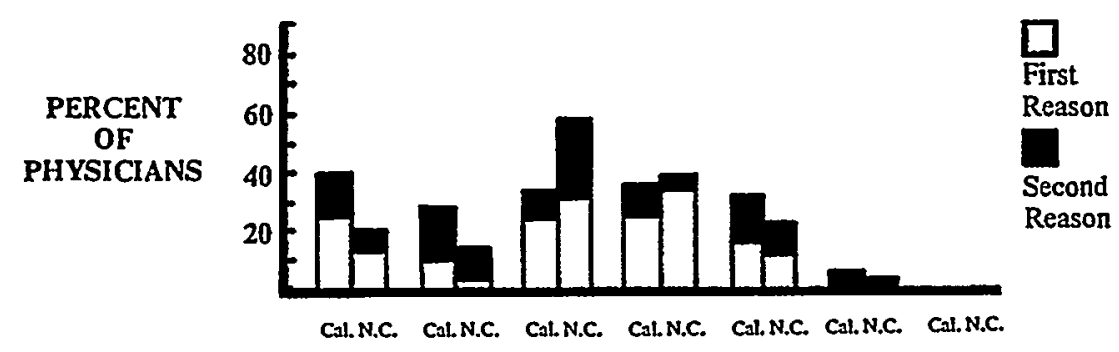

\begin{tabular}{|c|c|c|c|c|c|c|}
\hline $\begin{array}{l}\text { REASONS } \\
\text { FOR } \\
\text { FOLLOWING } \\
\text { PRACTICE }\end{array}$ & 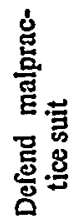 & 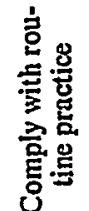 & 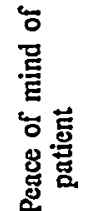 & 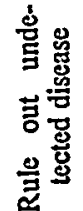 & 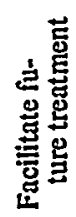 & 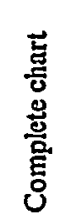 \\
\hline
\end{tabular}




\section{OTOLARYNGOLOGY}

When the patient complains of dizziness present several months following trauma, the otolaryngologist initially orders X-rays of the mastoids.

Figure 1. Cross-tabulation showing frequency sample physicians in California (Cal.) and North Carolina (N.C.) follow practice compared with their opinions as to utility of practice. Response in shaded area indicates failure to consider cost. (Sample size: 38 Cal.; 33 N.C.)

\section{FREQUENCY (\%Cal./\%N.C.)}

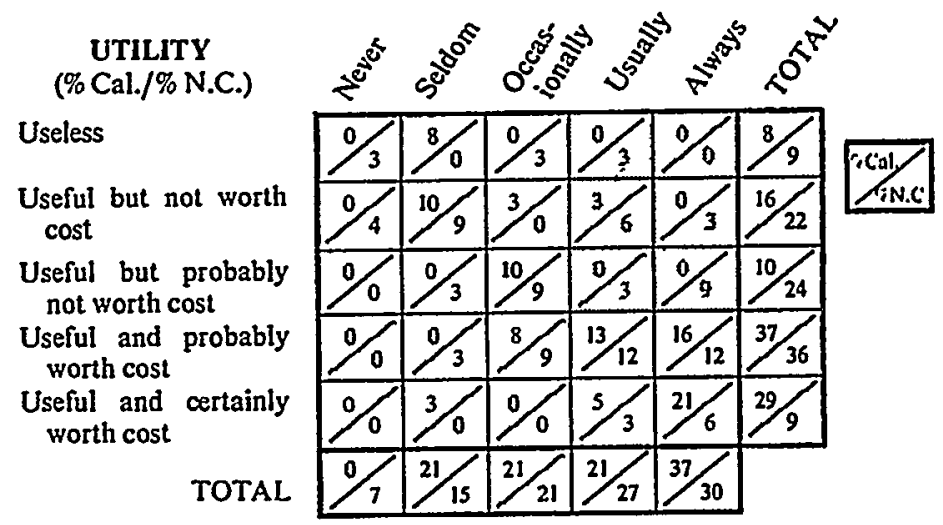

Figure 2. The first and second most important reasons to sample physicians for following this practice. (Sample size: 38 Cal.; 35 N.C.)

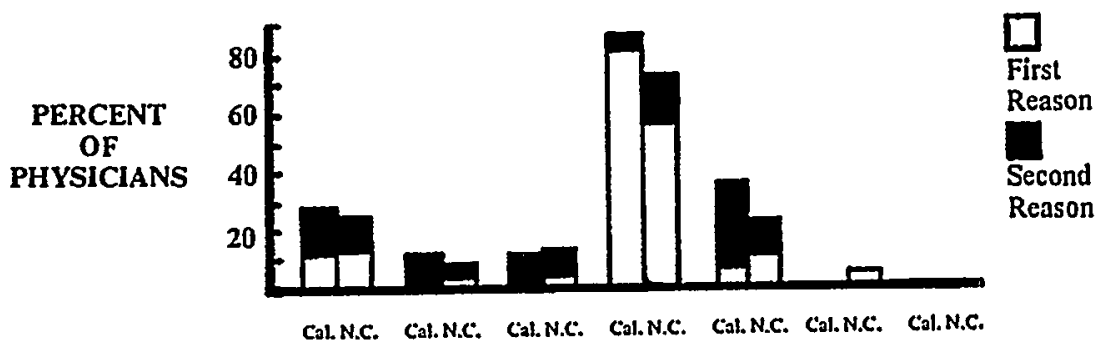

\begin{tabular}{|c|c|c|c|c|c|c|}
\hline $\begin{array}{c}\text { REASONS } \\
\text { FOR } \\
\text { FOLLOWING } \\
\text { PRACTICE }\end{array}$ & 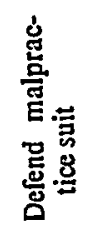 & 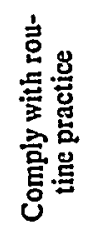 & 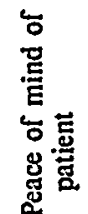 & 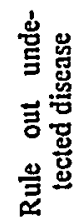 & 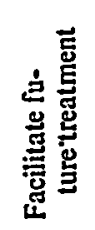 & 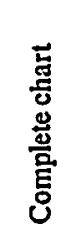 \\
\hline
\end{tabular}




\section{PEDIATRICS}

After making a preliminary diagnosis of "hyperkinetic child," the pediatrician requests psychiatric consultation.

Figure 1. Cross-tabulation showing frequency sample physicians in California (Cal.) and North Carolina (N.C.) follow practice compared with their opinions as to utility of practice. Response in shaded area indicates failure to consider cost. (Sample size: 43 Cal.; 56 N.C.)

\section{FREQUENCY (\%Cal./\%N.C.)}

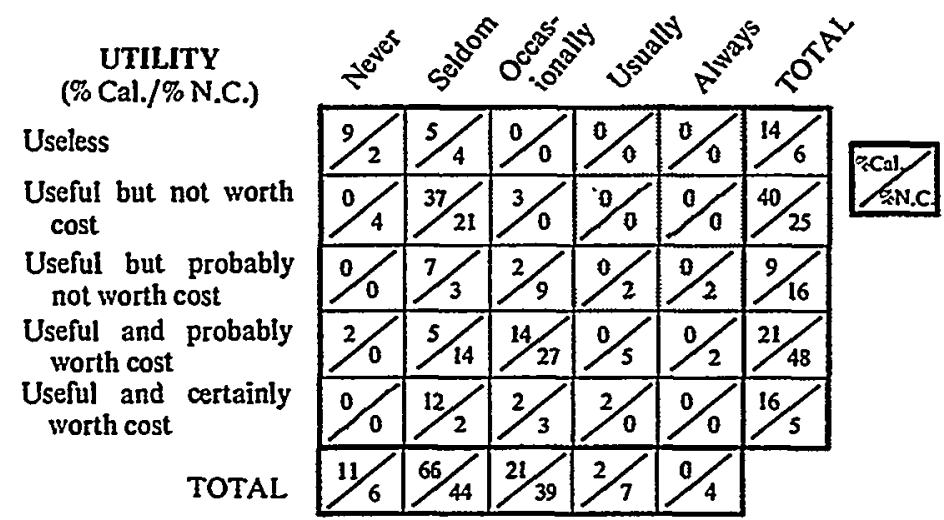

Figure 2. The first and second most important reasons to sample physicians for following this practice. (Sample size: 47 Cal.; 56 N.C.)

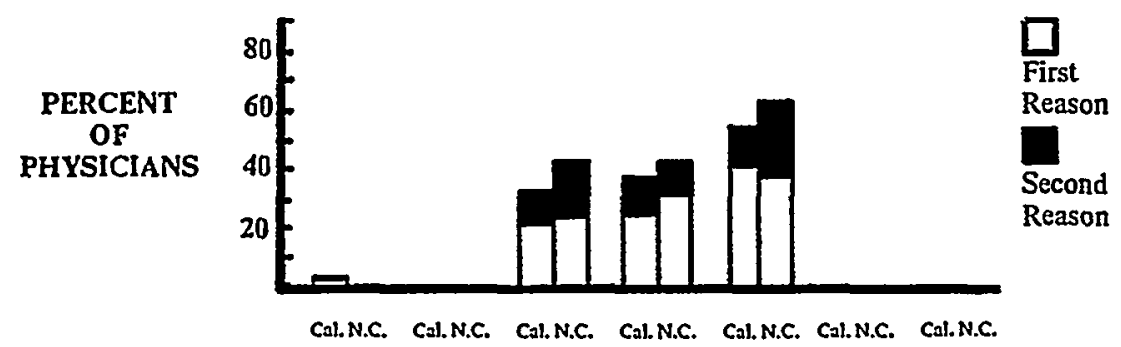

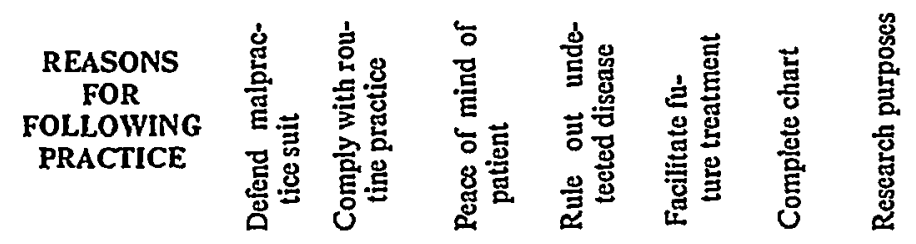




\section{PLASTIC SURGERY}

Prior to an operative procedure, the surgeon has photographs of the patient taken, shows the photographs to the patient, and has the patient sign a statement that each photograph is an accurate likeness.

Figure 1. Cross-tabulation showing frequency sample physicians in California (Cal.) and North Carolina (N.C.) follow practice compared with their opinions as to utility of practice. Response in shaded area indicates failure to consider cost. (Sample size: 47 Cal.; 9 N.C.)

\section{FREQUENCY (\%Cal./\%N.C.)}

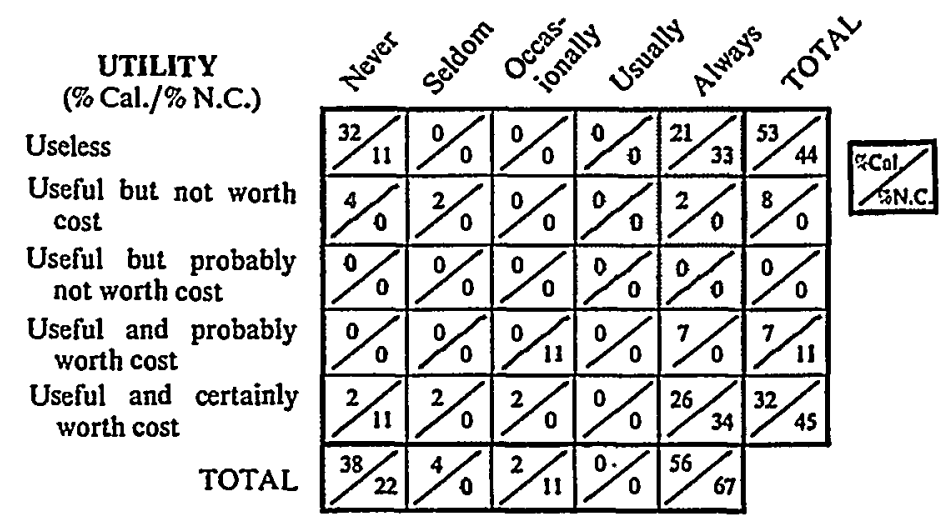

Figure 2. The first and second most important reasons to sample physicians for following this practice. (Sample size: 49 Cal.; 9 N.C.)

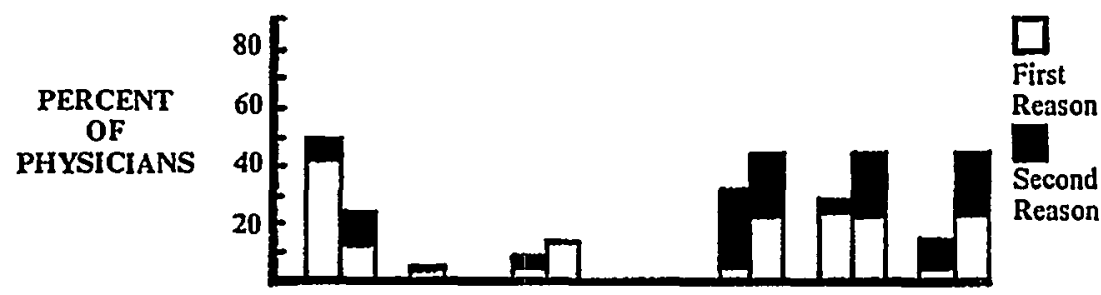

Cal.n.C. Cal.n.C. Cal.N.C. Cal.N.C. Cal.n.C. Cal.N.C. Cal.N.C.

\begin{tabular}{|c|c|c|c|c|c|c|}
\hline $\begin{array}{c}\text { REASONS } \\
\text { FOR } \\
\text { FOLLOWING } \\
\text { PRACTICE }\end{array}$ & 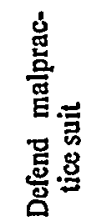 & 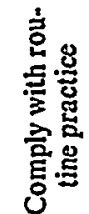 & 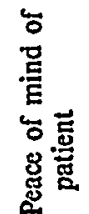 & 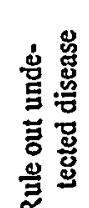 & 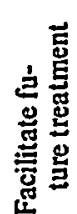 & 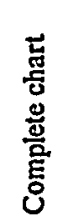 \\
\hline
\end{tabular}




\section{PSYCHIATRY}

When the patient exhibits symptoms of paranoia, the psychiatrist makes and preserves detailed records of examination and treatment as well as preserving all correspondence with the patient.

Figure 1. Cross-tabulation showing frequency sample physicians in California (Cal.) and North Carolina (N.C.) follow practice compared with their opinions as to utility of practice. Response in shaded area indicates failure to consider cost. (Sample size: 33 Cal.; 52 N.C.)

\section{FREQUENCY (\%Cal./\%N.C.)}

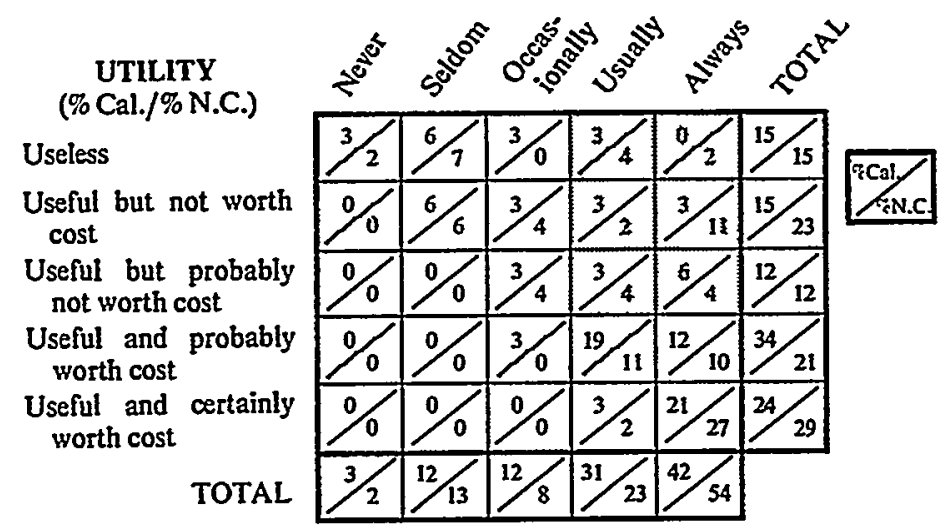

Figure 2. The first and second most important reasons to sample physicians for following this practice. (Sample size: 34 Cal.; 52 N.C.)

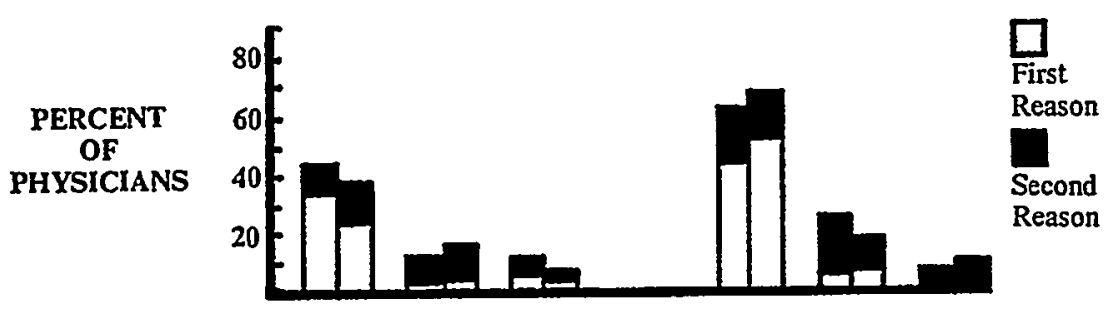

Cal.n.C. Cal.n.C. Cal.n.C. Cal.n.C. Cal.N.C. Cal.N.C. Cal.N.C.

\begin{tabular}{|c|c|c|c|c|c|c|}
\hline $\begin{array}{c}\text { REASONS } \\
\text { FOR } \\
\text { FOLLOWING } \\
\text { PRACTICE }\end{array}$ & 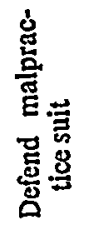 & 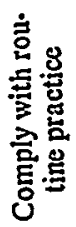 & 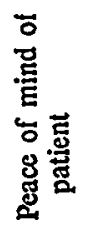 & 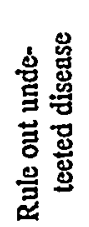 & 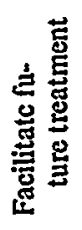 & 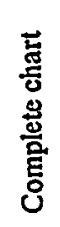 \\
\hline
\end{tabular}




\section{UROLOGY}

The patient is to undergo renal arteriography. The urologist orders an intradermal skin test in order to evaluate whether the patient is allergic to the radio-opaque solution used.

Figure 1. Cross-tabulation showing frequency sample physicians in California (Cal.) and North Carolina (N.C.) follow practice compared with their opinions as to utility of practice. Response in shaded area indicates failure to consider cost. (Sample size: 48 Cal.; 60 N.C.)

\section{FREQUENCX (\%Cal./\%N.C.)}

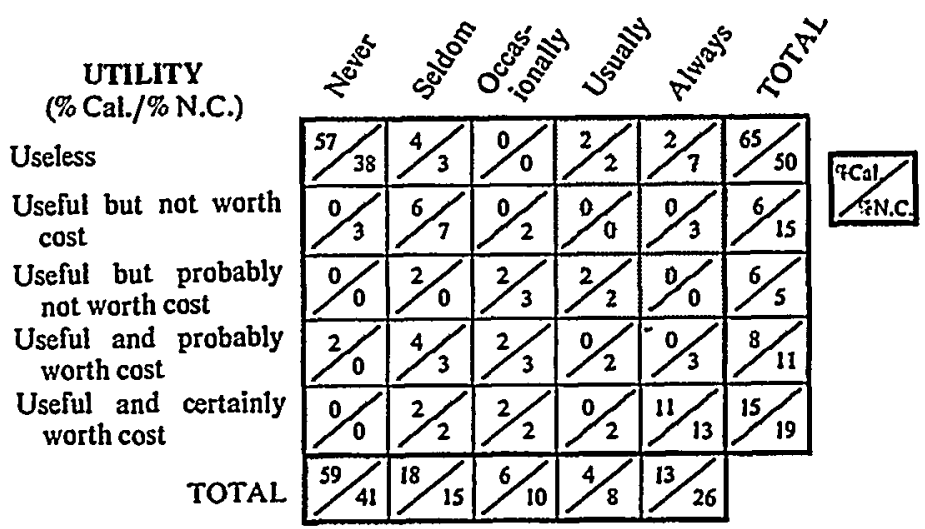

Figure 2. The first and second most important reasons to sample physicians for following this practice. (Sample size: 49 Cal.; 60 N.C.)

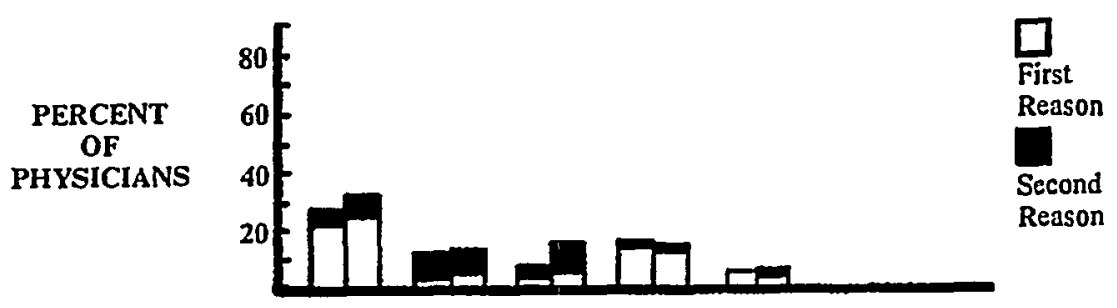

Cal.n.C. Cal.n.C. Cal.n.C. Cal.N.C. Cal.n.C. Cal.N.C. Cal.N.C.

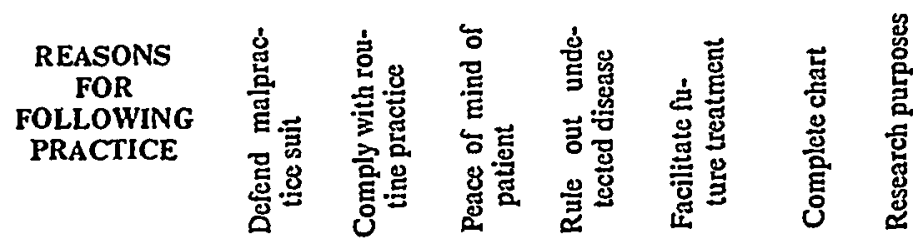




\section{UROLOGY}

Following urinary bladder instrumentation, the urologist administers antibiotics to combat possible genitourinary system infection.

Figure 1. Cross-tabulation showing frequency sample physicians in Califormia (Cal.) and North Carolina (N.C.) follow practice compared with their opinions as to utility of practice. Response in shaded area indicates failure to consider cost. (Sample size: 49 Cal.; 60 N.C.)

I FREQUENCY (\%Cal./\%N.C.)

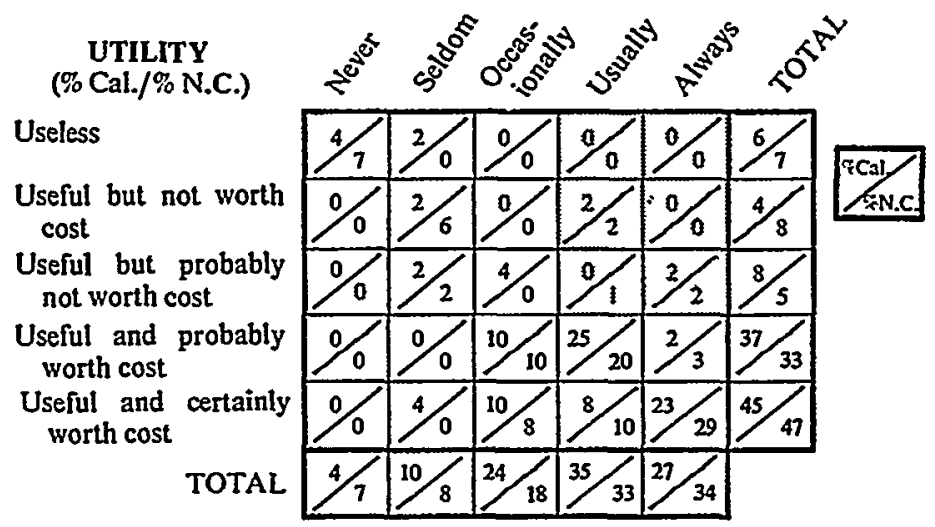

Figure 2. The first and second most important reasons to sample physicians for following this practice. (Sample size: 49 Cal.; 60 N.C.)

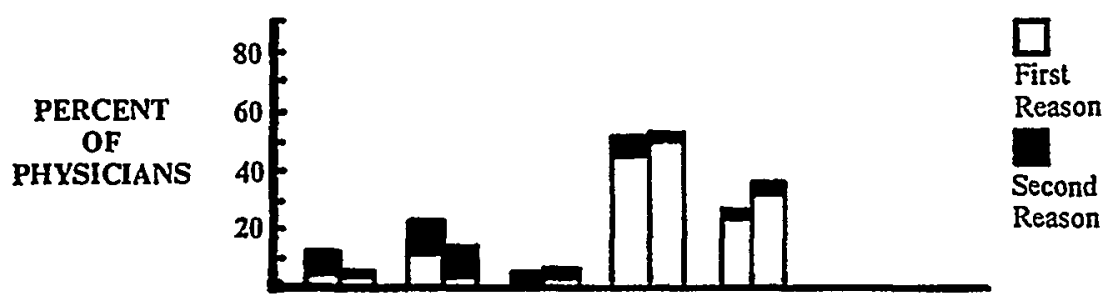

Cal.N.C. Cal.n.C. Cal.n.c. Cal.n.C. Cal.n.C. Cal.n.C. Cal.N.C.

\begin{tabular}{|c|c|c|c|c|c|c|}
\hline $\begin{array}{c}\text { REASONS } \\
\text { FOR } \\
\text { FOLLOWING } \\
\text { PRACTICE }\end{array}$ & 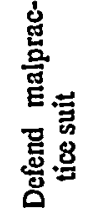 & 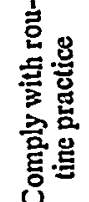 & 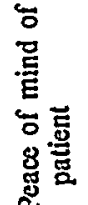 & 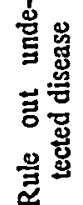 & 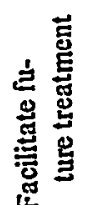 & 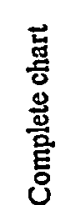 \\
\hline
\end{tabular}




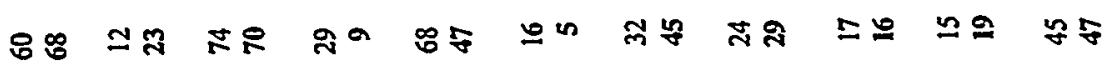

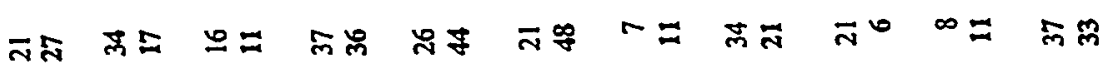

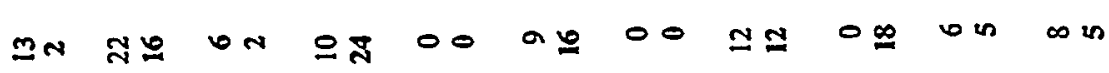

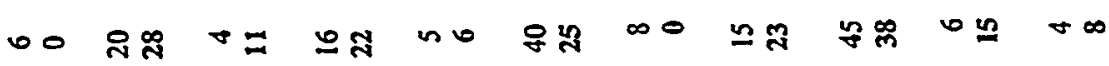

Om ํㅗㅇ

농

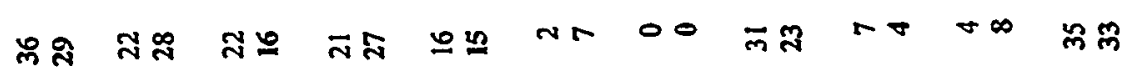
nm 오 우

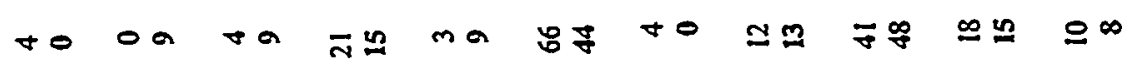

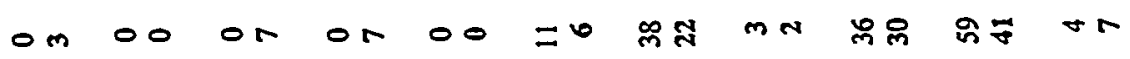

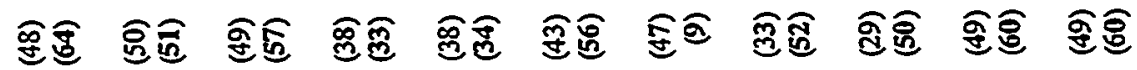

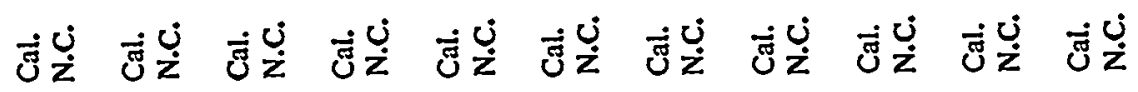

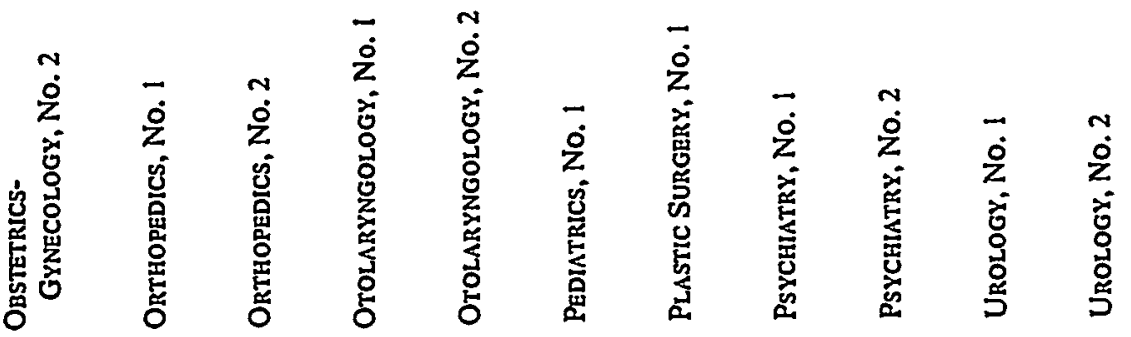


[Vol. 1971:939

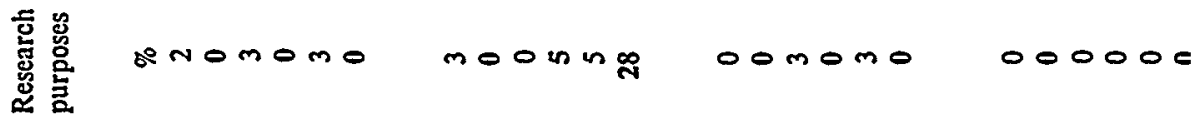

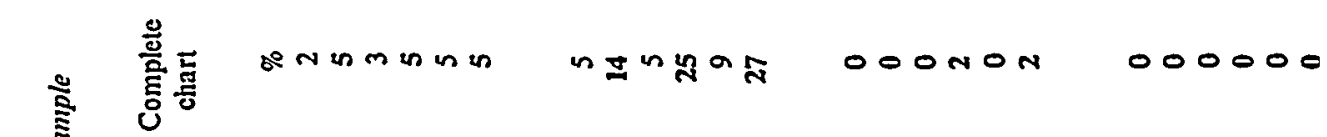

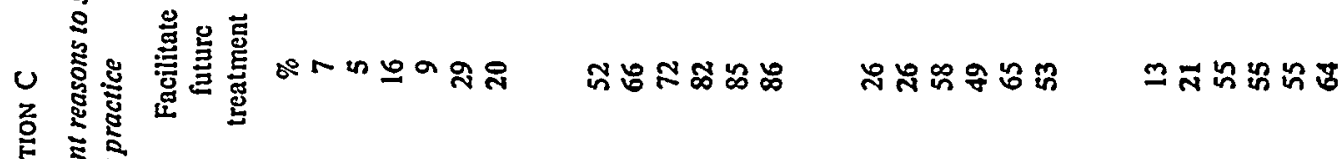

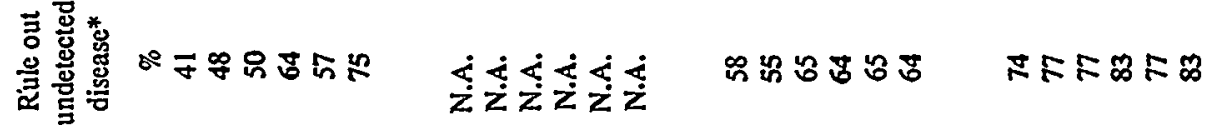

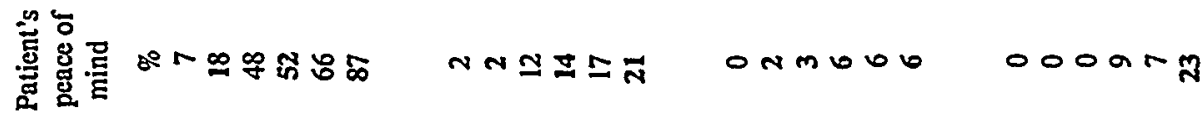

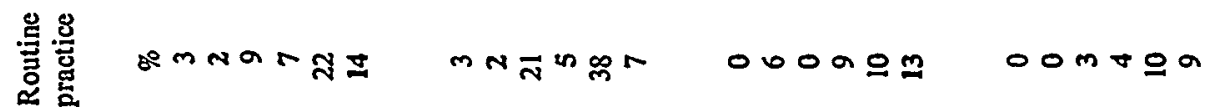

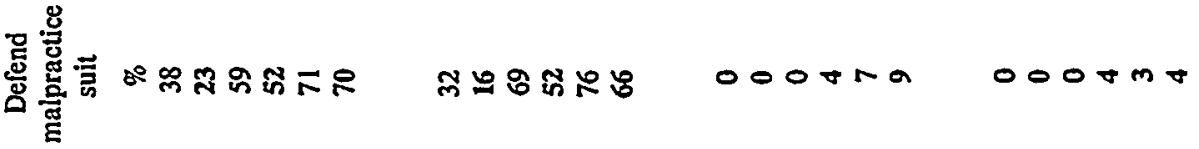

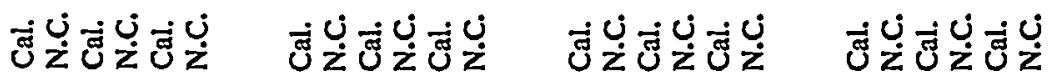

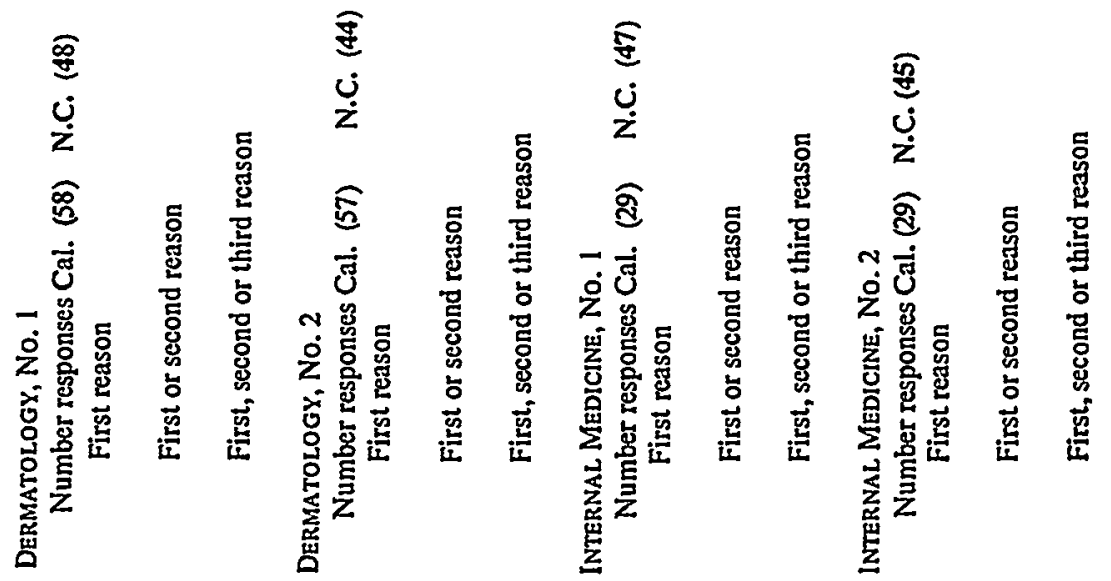


0000000000000000000000

000000 000000 0nonon 000000

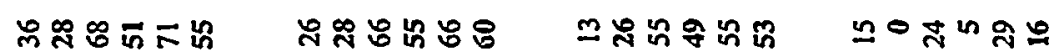

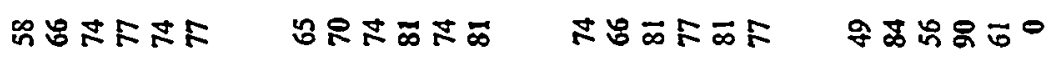

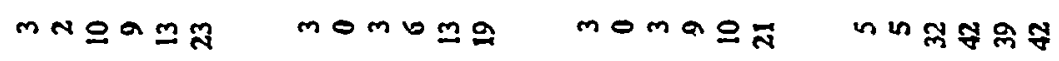

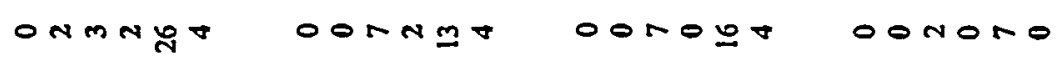

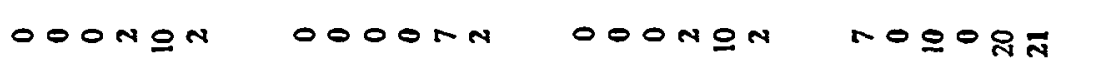

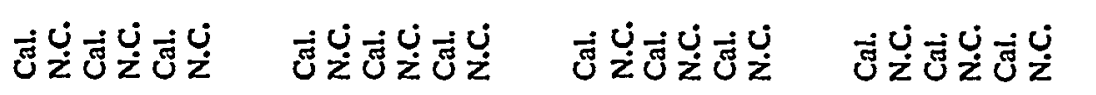

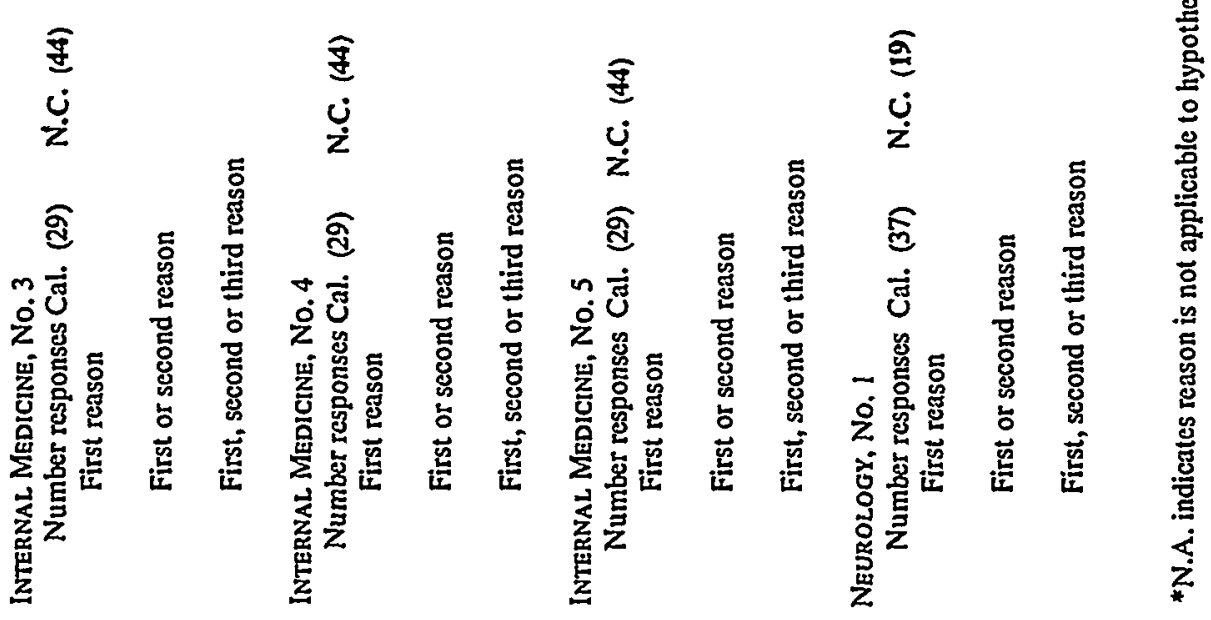


突总总 营蓆 总冚总

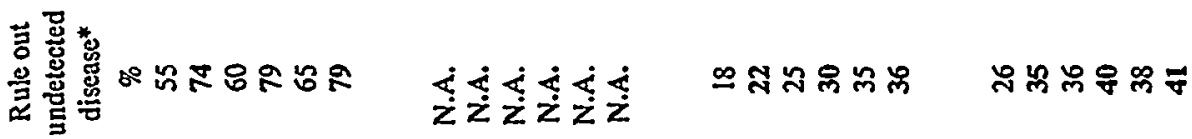

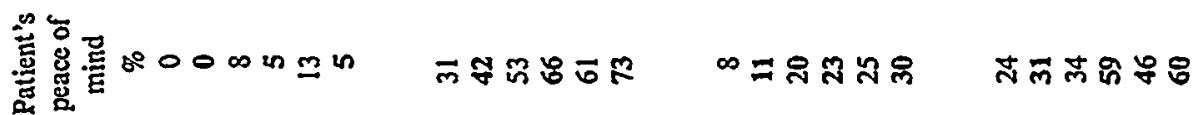

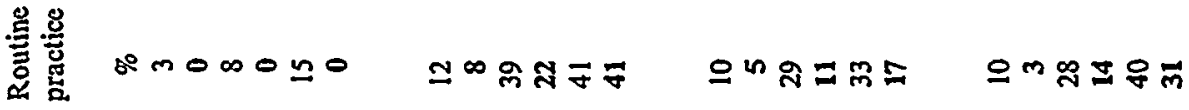

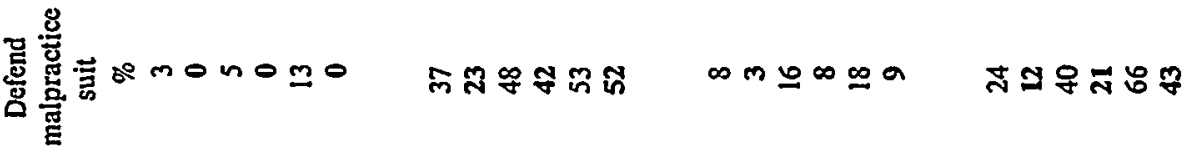

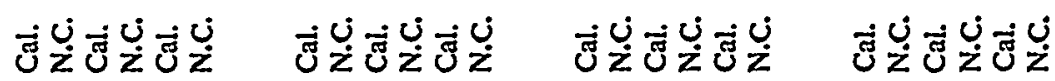

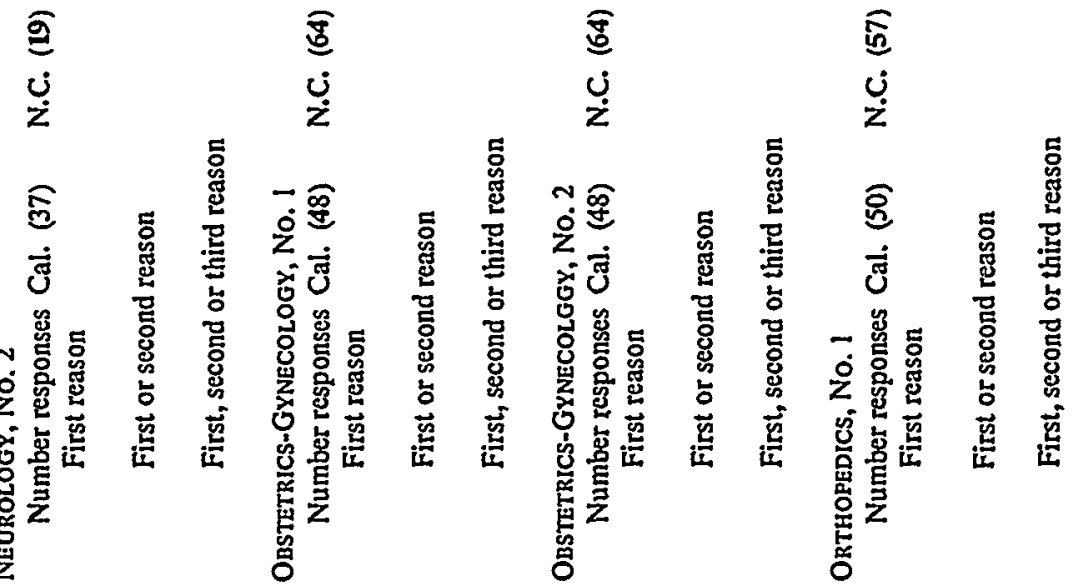




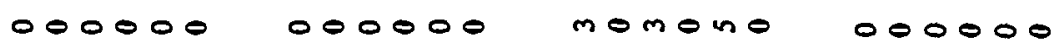

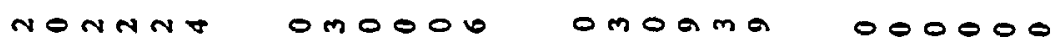

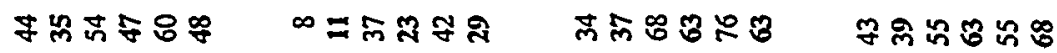

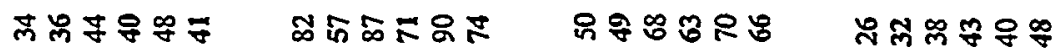

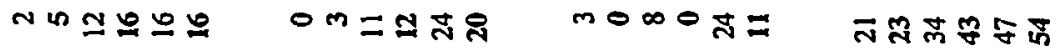

Rnd

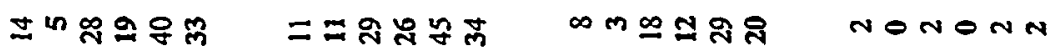

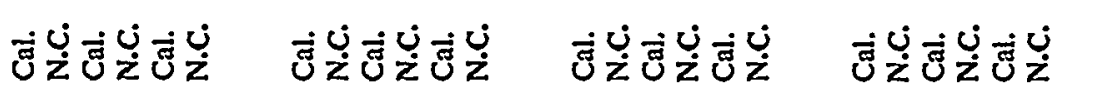

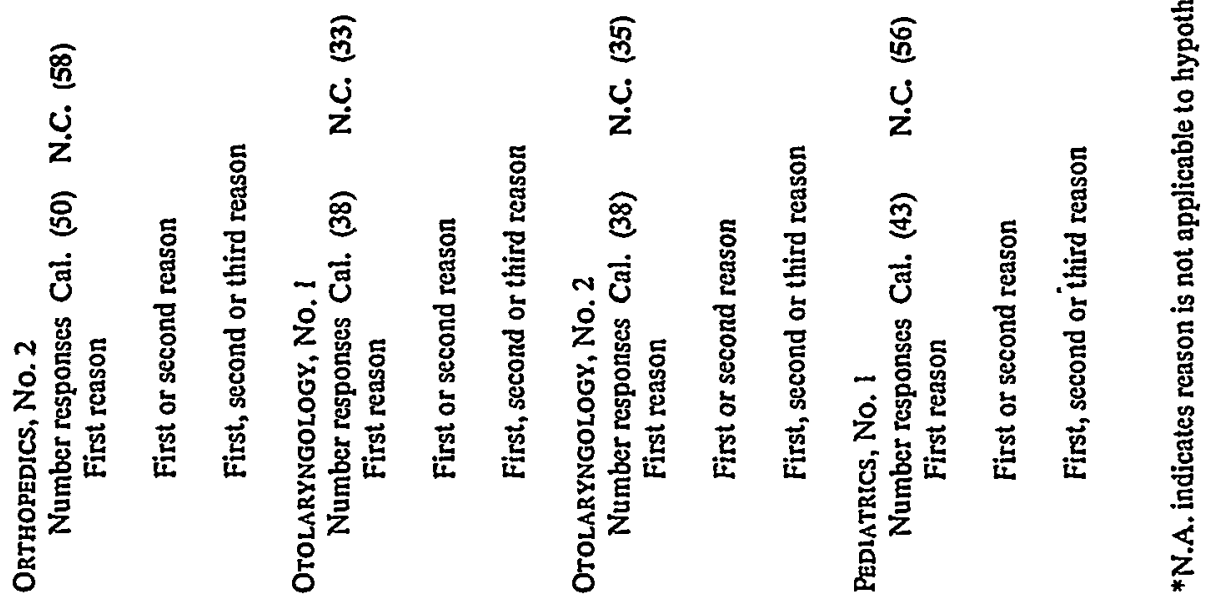


[Vol. 1971:939

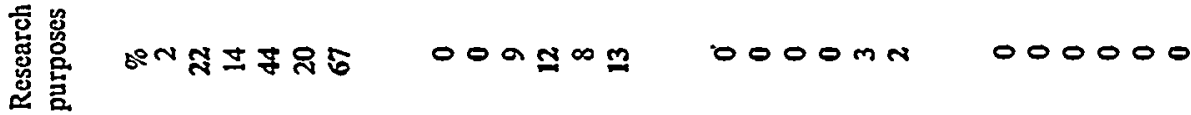

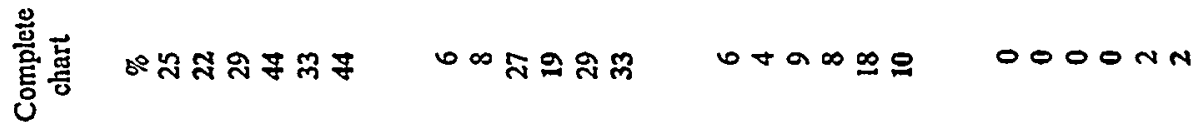

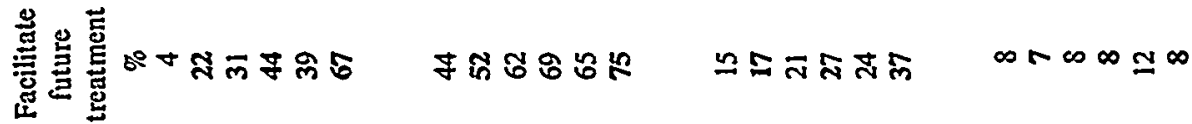

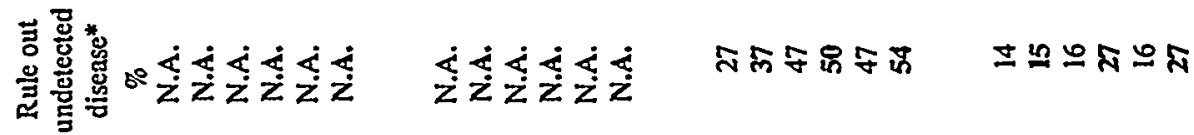

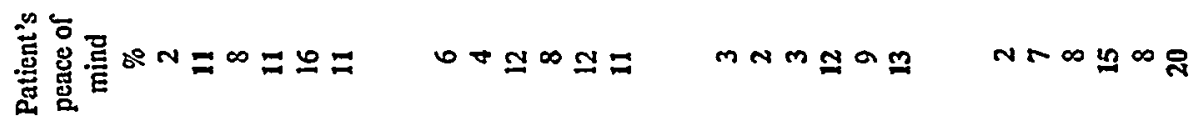

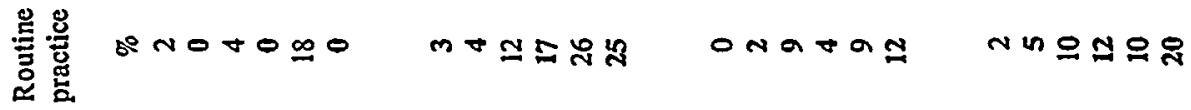

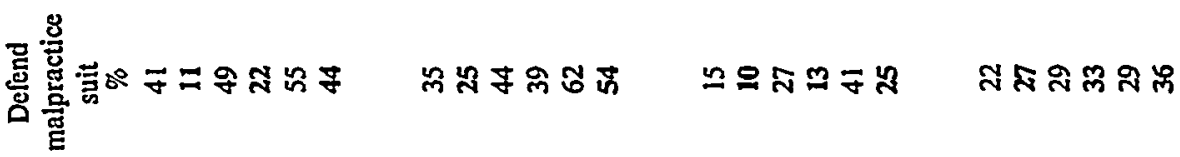

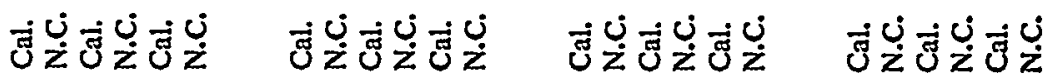

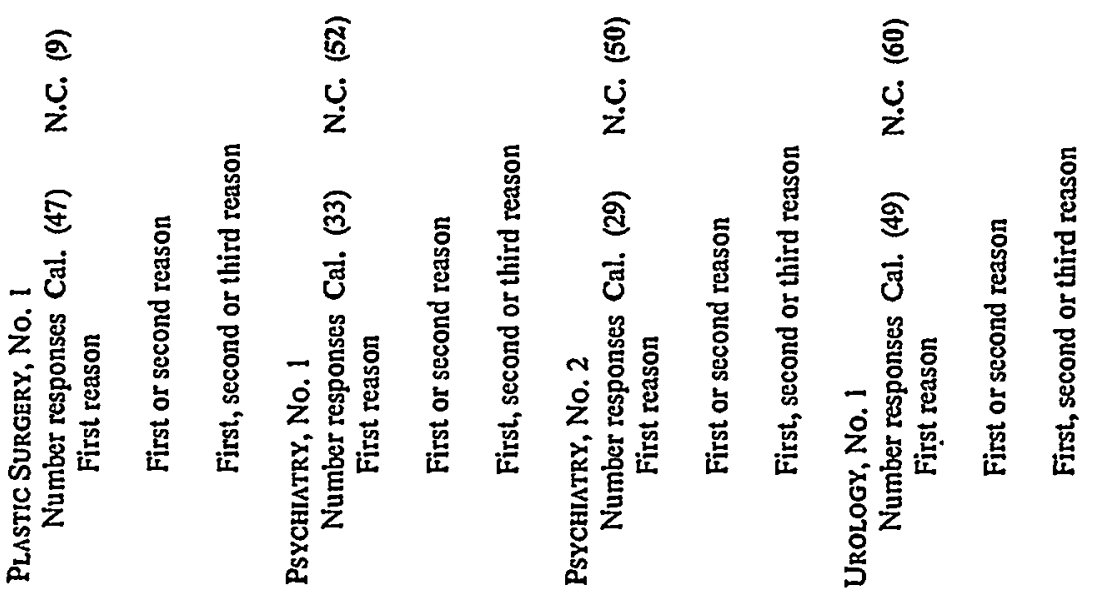


000000

000000

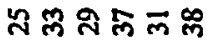

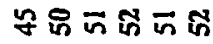

ontror

으ำกำำ

$0 m \simeq 5 \infty$ 
